\title{
Investigation of Substrate Activation by 4-Chlorobenzoyl-Coenzyme A Dehalogenase $^{\dagger}$
}

\author{
Kimberly L. Taylor, Hong Xiang, Rui-Qin Liu, Guang Yang, and Debra Dunaway-Mariano* \\ Department of Chemistry and Biochemistry, University of Maryland, College Park, Maryland 20742
}

Received November 6, $1996^{\otimes}$

\begin{abstract}
Chlorobenzoyl-coenzyme A (4-CBA-CoA) dehalogenase catalyzes the hydrolysis of 4-CBACoA to 4-hydroxybenzoyl-coenzyme A (4-HBA-CoA), using the carboxylate side chain of aspartate 145 to displace the chloride from $\mathrm{C}(4)$ of the benzoyl ring. Previous UV-visible, Raman, and ${ }^{13} \mathrm{C} N \mathrm{NR}$ studies of enzyme-bound substrate analog or product ligand indicated that the environment of the enzyme active site induces a significant reorganization of the benzoyl ring $\pi$-electrons. This observation was interpreted as evidence for electrophilic catalysis [ $\mathrm{viz}$. active-site-induced polarization of electron density away from the ring C(4)] [Taylor, K. L., Liu, R.-Q., Liang, P.-H., Price, J., Dunaway-Mariano, D., Tonge, P. J., Clarkson, J., \& Carey, P. R. (1995) Biochemistry 34, 13881]. The recent crystal structure of the dehalogenase -4 -HBA-CoA complex reveals two hydrogen bonds contributed to the benzoyl $\mathrm{C}=\mathrm{O}$ by the backbone amide protons of Gly114 and Phe64 and a possible dipolar interaction with the positive pole of the 114-121 $\alpha$-helix. Residues closely surrounding the benzoyl ring include W137, D145, W89, F64, F82, and H90. In the present study, the mutants D145A, H90Q, W137F, W89F, W89Y, F64L, F82L, and G114A were prepared to examine the effect of amino acid substitution on catalysis and on perturbation of the UV-visible spectral properties of the substrate benzoyl ring. Substitution of the two catalytic residues D145 and H90 inhibited catalysis but not ligand binding or the induction of the red shift in the benzoyl ring absorption. These two residues do not appear to contribute to substrate benzoyl ring binding or polarization. The F64L, F82L, W89F, and W137F mutants retained substantial catalytic activity and the ability to induce the red shift. The W89Y mutant, on the other hand, is inhibited in catalysis and ligand binding, suggesting that hydrophobicity more than packing may be critical for the benzoyl ring binding/activation. The G114A mutant was shown to be strongly inhibited in both substrate binding and activation, indicating that H-bonding and/or interaction with the dipole of the 114-121 $\alpha$-helix may be crucial.
\end{abstract}

4-Chlorobenzoyl-coenzyme A (4-CBA-CoA $)^{1}$ dehalogenase catalyzes the hydrolytic dehalogenation of 4-CBA-CoA to 4-hydroxybenzoyl-coenzyme A (4-HBA-CoA). This enzyme functions in the 4-CBA to 4-HBA converting pathway found in certain strains of soil-dwelling bacteria adapted to the use of 4-CBA as an alternate carbon source (Scholten et al., 1991; Copely et al., 1992; Groenewegen et al., 1992; Adriaens et al., 1989). Recent studies of the dehalogenase from Pseudomonas sp. strain CBS3 have revealed a unique mechanism of catalysis in which an activesite carboxylate adds to the $\mathrm{C}(4)$ of the benzoyl ring of the bound substrate to form a Meisenheimer complex as the first reaction intermediate (Yang et al., 1994; Liu et al., 1995; Yang et al., 1996) (see Scheme 1). Expulsion of the chloride from the Meisenheimer complex with concomitant rearomatization of the benzoyl ring generates an arylated enzyme as the second reaction intermediate. Hydrolysis of the arylated enzyme occurs by addition of a water molecule to the acyl carbonyl carbon. The tetrahedral intermediate

\footnotetext{
$\dagger$ This work was supported by NIH Grant GM-36360.

* To whom correspondence should be addressed.

${ }^{\otimes}$ Abstract published in Advance ACS Abstracts, January 15, 1997.

${ }^{1}$ Abbreviations: 4-CBA, 4-chlorobenzoate; 4-CBA-CoA, 4-chlorobenzoyl-coenzyme A; 4-HBA, 4-hydroxybenzoate; 4-HBA-CoA, 4-hydroxybenzoyl-coenzyme A; 4-MeBA-CoA, 4-methylbenzoyl-coenzyme A; tiglyl-CoA, trans-2-butenoyl-CoA; $\mathrm{K}^{+}$-Hepes, [N-(2-hydroxyethyl)piperazine- $N^{\prime}$-(2-ethanesulfonic acid)] potassium salt.
}

thus formed expels the hydroxybenzoyl group to regenerate the catalytic carboxylate residue and form the 4-HBA-CoA product.

In a previous study of the spectral properties of 4-methylbenozyl-CoA (4-MeBA-CoA; a substrate analog) and 4-HBACoA (the reaction product) bound to 4-CBA-CoA dehalogenase active site, we had concluded that the environment of the active site strongly polarizes the $\pi$-electron density in the ligand benzoyl ring (Taylor et al., 1995). Now that the X-ray crystal structure of the dehalogenase-4-HBA-CoA complex has been solved (Benning et al., 1996), the disposition of active-site side chains around the ligand benzoyl ring is known. The active-site residues, pictured in Figure 1, include Asp145, the nucleophile; His90, the base catalyst; and the aromatic residues W137, W89, F64, and F82, whose rings form a $\pi$-electron cloud encircling the benzoyl ring (Yang et al., 1996; Benning et al., 1996). In addition, the benzoyl $\mathrm{C}=\mathrm{O}$ lies within $\mathrm{H}$-bond distance of the backbone amide hydrogen atoms of Gly114 and Phe64. Gly114, which is located at the end of a helix that runs Gly114-Ala121, appears to be the conduit for benzoyl $\mathrm{C}=\mathrm{O}$ interaction with the positive pole of the helix dipole. From this structure, a picture of electrophilic catalysis emerges in which electron density is withdrawn from the ring through the two backbone amide hydrogen bonds formed with the benzoyl $\mathrm{C}=\mathrm{O}$, thus facilitating the approach of the charged Asp145 carboxylate group to $\mathrm{C}(4)$. The hydrophobic 
Scheme 1: Proposed Chemical Pathway of the 4-CBA-CoA Dehalogenase-Catalyzed Hydrolysis of 4-CBA-CoA to 4-HBA-CoA ${ }^{a}$
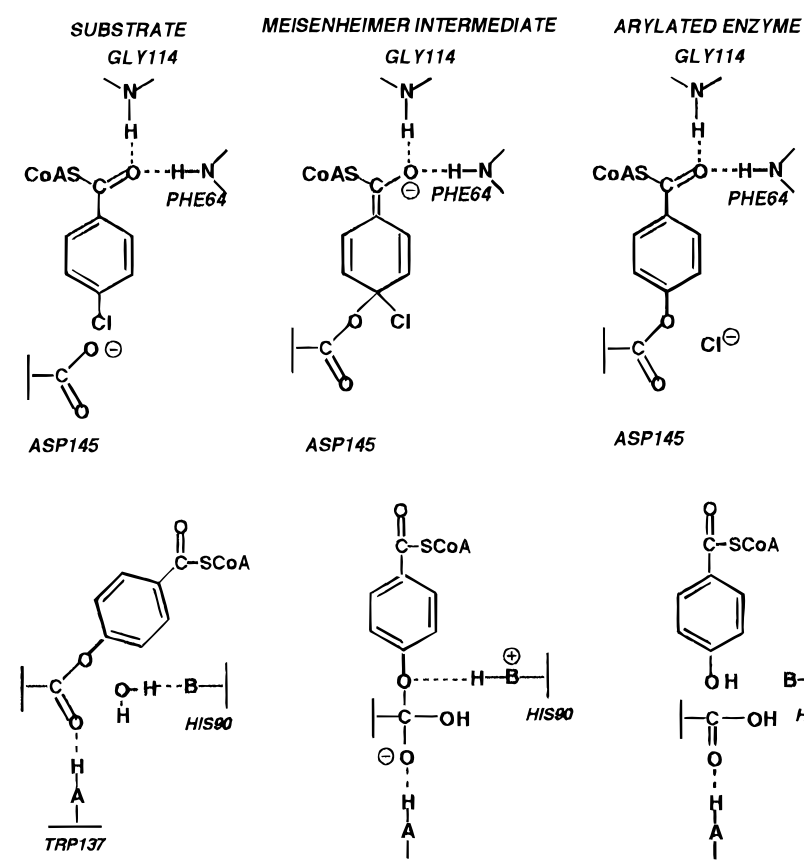

ARYLATED ENZYME
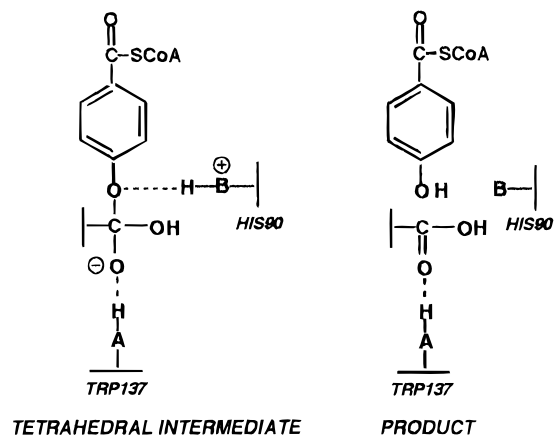

${ }^{a}$ Liu et al. (1995); Benning et al. (1996); Yang et al. (1996).

environment provided by the aromatic side chains of W89, W137, F64, and F82 may enhance the electrostatic interaction between substrate and enzyme.

In this paper, we examine the roles played by the activesite residues in anchoring and polarizing the substrate. For the studies that are described, site-directed mutagenesis techniques were used to replace the active-site amino acids, UV-visible absorption and ${ }^{13} \mathrm{C}$ NMR techniques were used to detect perturbation of electron density in the benzoyl moiety of the ligand bound to the mutant enzyme, and kinetic/thermodynamic techniques were used to evaluate the efficiency of catalysis/ligand binding in the mutant enzyme.

\section{MATERIALS AND METHODS}

General. $\left[{ }^{13} \mathrm{C}=\mathrm{O}\right]-4$-Hydroxybenzoic acid was purchased from Isotec Inc. [thioester $\left.{ }^{13} \mathrm{C}=\mathrm{O}\right]-4-\mathrm{HBA}-\mathrm{CoA}$ was synthesized from this compound by modifying the procedure reported by Mieyal et al. (1974) and Merkel et al. (1989) as described in Liang et al. (1993). 4-HBA-CoA and 4-CBACoA were prepared according to Liang et al. (1993), 4-MeBA-CoA according to Taylor et al. (1995), and 4-HBApantetheine and 4-CBA-pantetheine according to Taylor (1996). Phenylacetyl-CoA, propionyl-CoA, and tiglyl-CoA were purchased from Sigma Chemical Co. 4-CBA-CoA dehalogenase (specific activity $=1.5$ units $/ \mathrm{mg}$ ) was prepared according to the procedure of Chang et al. (1992) as modified in Liang et al. (1993). Dehalogenase concentrations were determined by using the Bradford method (Bradford, 1976) and a subunit molecular mass of $30 \mathrm{kDa}$ (and are reported as active-site concentrations). Enzyme spectrophotometric assays were carried out as previously described (Chang et al., 1992; Liang et al., 1993).

Preparation and Purification 4-CBA-CoA Dehalogenase Mutants. Dehalogenase mutants G114P, G114A, W89F,
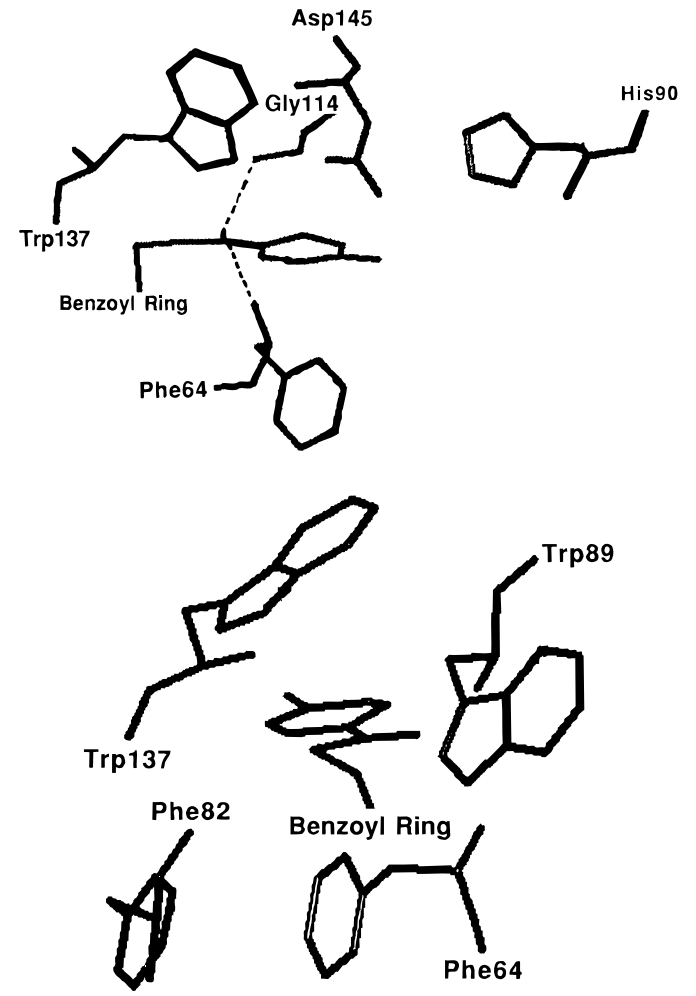

FIGURE 1: Active-site region of wild-type 4-CBA-CoA dehalogenase derived from the crystal structure of the dehalogenase-4-HBACoA complex determined at $1.8 \AA$ (Benning et al., 1996), showing (top) the arrangement of the Trp137, Asp145, and His90 side chains around the ligand hydroxybenzoyl ring and the positions of the Gly114 and Phe64 amide backbone NHs relative to the benzoyl $\mathrm{C}=\mathrm{O}$ and (bottom) the arrangement of the Phe64, Phe82, Trp137, and Trp89 side chains around the ligand hydroxybenzoyl ring.

W89Y, and F64L were prepared by using essentially the same protocol described in Yang et al. (1996) for the preparation of D145A, H81Q, H90Q, and W137F 4-CBACoA dehalogenase mutants. The specific base substitutions, location of primers, and restriction enzymes used are as follows: base substitutions, GGT to CCT for G114P, GGT to GCT for G114A, TGG to TTC for W89F, TGG to TAT for W89Y, TTC to CTC for F82L, and TTC to CTT for F64L; outside primers, 462-477 and 1493-1508; inside primers, $942-962$ for W89F and W89Y, 921-939 for F82L, 868-886 for F64L, and 1017-1035 for G114P and G114A; restriction enzymes, $M l u \mathrm{I}, N r u \mathrm{I}$, and BstBI. The purification of the W89F, W89Y, F64L, and F82L mutant proteins was carried out in essentially the same manner described for the W137F mutant in Yang et al. (1996). The yields of these mutants are $50,100,100$, and $20 \mathrm{mg}$ of pure protein/25 $\mathrm{g}$ of wet cell paste. The G114P mutant proved to be too unstable to isolate. The G114A mutant was purified as follows: Escherichia coli BL21(DE3) cells (25 g) were suspended in $250 \mathrm{~mL}$ of $0.1 \mathrm{M} \mathrm{NaCl}$ in buffer [50 $\mathrm{mM} \mathrm{K}^{+}$-HEPES $(\mathrm{pH}$ 7.5) and $2 \mathrm{mM}$ DTT] and then passed through a French press at 1000 psi. Following centrifugation at $8000 \mathrm{~g}$ for $20 \mathrm{~min}$, the supernatant was decanted and diluted to $500 \mathrm{~mL}$ with buffer. To this stirred solution, 10\% Polymin P (v/v) (polyethylenimine) was slowly added to a final concentration of $0.4 \%$. The precipitant was isolated by centrifugation and then suspended in $120 \mathrm{~mL}$ of $1 \mathrm{M} \mathrm{NaCl}$ in buffer. Following centrifugation to remove insoluble material, the protein was precipitated from the solution with the addition of solid ammonium sulfate to $70 \%$ saturation. The protein precipitate 
was collected by centrifugation, dissolved in buffer, and dialyzed at $4{ }^{\circ} \mathrm{C}$ against two changes of $2 \mathrm{~L}$ of buffer. The dialysate was chromatographed on a $2.5-\times 40$-cm DEAEcellulose column using $200 \mathrm{~mL}$ of buffer followed by a 1-L linear gradient of $\mathrm{KCl}(0.0-0.5 \mathrm{M})$ in buffer as eluant. The dehalogenase-containing fractions (identified by SDSPAGE; eluted at $c a .0 .25 \mathrm{M} \mathrm{KCl}$ ) were chromatographed on a hydroxyapatite column $(2.5 \times 40 \mathrm{~cm})$ equilibrated with buffer. The column was eluted with $200 \mathrm{~mL}$ of $0.05 \mathrm{M}$ $\mathrm{K}_{2} \mathrm{HPO}_{4}$ in buffer followed by $0.6 \mathrm{~L}$ of a linear gradient of $0.05-0.5 \mathrm{M} \mathrm{K}_{2} \mathrm{HPO}_{4}$. The G114A dehalogenase eluted at ca. $0.3 \mathrm{M} \mathrm{K}_{2} \mathrm{HPO}_{4}$ providing $20 \mathrm{mg}$ of pure protein. The homogeneity of the purified mutant proteins was verified by SDS-PAGE analysis.

Measurement of the Catalytic Activity and Competitive Inhibition of Wild-Type and Mutant Dehalogenases. The steady-state kinetic catalytic constants $V_{\max }$ and $K_{\mathrm{m}}$ and the competitive inhibition constant $K_{\mathrm{i}}$ were measured for wildtype $(0.04 \mu \mathrm{M}), \mathrm{G} 114 \mathrm{~A}(2.5 \mu \mathrm{M}), \mathrm{W} 137 \mathrm{~F}(2.6 \mu \mathrm{M})$, W89F $(2.0 \mu \mathrm{M})$, F64L $(0.7 \mu \mathrm{M})$, and F82L $(0.5 \mu \mathrm{M})$ dehalogenasecatalyzed dehalogenation of 4-CBA-CoA using initial velocity techniques in conjunction with the continuous spectrophotometric assay described in Liang et al. (1993). Reactions, carried out in 1-mL cells containing 4-70 $\mu \mathrm{M}$ 4-CBA-CoA (except for the G114A mutant where $40-400 \mu \mathrm{M} 4$-CBACoA was used) in $50 \mathrm{mM} \mathrm{K}^{+}$-HEPES $\left(\mathrm{pH} 7.5,25^{\circ} \mathrm{C}\right.$ ), with or without inhibitor $(18$ and $30 \mu \mathrm{M}$ for 4-MeBA-CoA inhibition of W89F, F64L, and F82L, 3 and $6 \mu \mathrm{M}$ for $\mathrm{W} 137 \mathrm{~F}$, and 10 and $20 \mu \mathrm{M}$ for wild type); 3.4 and $6.7 \mu \mathrm{M}$ for 4-HBA-CoA inhibition of wild type, 4.5 and $9.0 \mu \mathrm{M}$ for W89F, 4.3 and $8.6 \mu \mathrm{M}$ for F64L and W137F, and 2.7 and $5.5 \mu \mathrm{M}$ for $\mathrm{F} 82 \mathrm{~L})$, were monitored at $300 \mathrm{~nm}(\Delta \epsilon=8200$ $\mathrm{M}^{-1} \mathrm{~cm}^{-1}$ ). The inhibition of wild-type dehalogenase with tiglyl-CoA and propionyl-CoA was carried out using 3-40 $\mu \mathrm{M}$ 4-CBA-CoA and inhibitor concentrations of 5 and 80 $\mu \mathrm{M}$, respectively. The initial velocity data were analyzed using eqs 1 and 2 and the FORTRAN HYPERL and COMPL programs of Cleland (1979):

$$
\begin{gathered}
V_{0}=V_{\text {max }}[\mathrm{A}] /\left([\mathrm{A}]+K_{\mathrm{m}}\right) \\
V_{0}=V_{\max }[\mathrm{A}] /\left[K_{\mathrm{m}}\left(1+[\mathrm{I}] / K_{\mathrm{i}}\right)+[\mathrm{A}]\right]
\end{gathered}
$$

where $V_{0}=$ initial velocity, $V_{\max }=$ maximum velocity, [A] $=$ substrate concentration, $K_{\mathrm{m}}=$ Michaelis constant, [I] $=$ inhibitor concentration, and $K_{\mathrm{i}}=$ the inhibition constant. The $k_{\text {cat }}$ was calculated from $V_{\max } /[$ enzyme].

The catalytic activity of the W89Y dehalogenase was tested at a concentration of $25 \mu \mathrm{M}$ with $500 \mu \mathrm{M}$ 4-CBA-

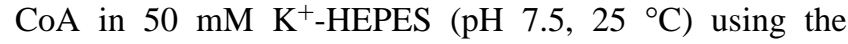
spectrophotometric assay. No change in absorbance at 300 $\mathrm{nm}$ was detected within a 3-h period, and therefore, the mutant was considered catalytically inactive.

UV-Visible Absorption Difference Spectral Analysis of the Formation of 4-HBA-CoA Complexes with Wild-Type and Mutant 4-CBA-CoA Dehalogenase. UV-Visible absorption reference spectra were measured using 1-mL quartz tandem cells containing $0.5 \mathrm{~mL}$ of enzyme solution $(50 \mu \mathrm{M})$ in one compartment and $0.5 \mathrm{~mL}$ of 4-HBA-CoA or 4-MeBA-CoA solution $(200 \mu \mathrm{M})$ in the other. All solutions were buffered with $50 \mathrm{mM} \mathrm{K}^{+}$-HEPES, $\mathrm{pH} 7.5$, at $25^{\circ} \mathrm{C}$. The reference absorbance spectrum was recorded and subtracted from the spectrum of the mixed solutions to give the difference spectra of the enzyme-4-HBA-CoA or enzyme-4-MeBA-CoA complex.

The dissociation constants $\left(K_{\mathrm{d}}\right)$ of the enzyme-4-MeBACoA and enzyme-4-HBA-CoA complexes were measured by spectral titration. The absorbance due to the enzymeligand complex, determined from the difference spectrum, was measured as a function of ligand concentration at fixed enzyme concentration (10 or $25 \mu \mathrm{M}$ in $50 \mathrm{mM} \mathrm{K}^{+}$-HEPES, $\left.\mathrm{pH} 7.5,25^{\circ} \mathrm{C}\right)$. The 4-MeBA-CoA titrations were monitored at the $302-308-\mathrm{nm} \lambda_{\max }$, while the 4-HBA-CoA titrations were monitored at the $373-$ or $330-\mathrm{nm} \lambda_{\max }$. The titration data were fit to the quadratic equation (eq 3 ) described by Anderson et al. (1988) using the Kaleida Graph Computer program for nonlinear regression, to obtain the dissociation constant $\left(K_{\mathrm{d}}\right)$ of the enzyme-ligand complex.

$$
\begin{aligned}
\Delta A=\left(\Delta A_{\text {max }} /\left[\mathrm{E}_{0}\right]\right)\left\{\left(K_{\mathrm{d}}^{\mathrm{app}}+\left[\mathrm{E}_{0}\right]+\left[\mathrm{S}_{0}\right]\right)-\right. \\
\left.\left(\left(K_{\mathrm{d}}^{\text {app }}+\left[\mathrm{E}_{0}\right]+\left[\mathrm{S}_{0}\right]\right)^{2}-4\left[\mathrm{E}_{0}\right]\left[\mathrm{S}_{0}\right]\right)^{1 / 2}\right\} / 2
\end{aligned}
$$

In eq 3, $\Delta A_{\max }=$ the total change in absorbance, $\Delta A=$ the observed change in absorbance, $\left[\mathrm{E}_{0}\right]=$ the total enzyme concentration, $\left[\mathrm{S}_{0}\right]=$ ligand concentration, and $K_{\mathrm{d}}=$ dissociation constant.

${ }^{13} \mathrm{C}$ NMR Spectral Measurements of [thioester $-{ }^{13} \mathrm{C}=\mathrm{O}$ ]4-HBA-CoA Bound to the Active Site of Wild-Type and Mutant 4-CBA-CoA Dehalogenase. NMR samples were prepared as follows. Twenty-five milliliters of dehalogenase $\left(\mathrm{OD}_{280}=3.7\right)$ in $50 \mathrm{mM} \mathrm{K}^{+}$-HEPES and $1 \mathrm{mM}$ DTT, $\mathrm{pH}$ 7.5 , was concentrated to $2 \mathrm{~mL}$ using a Amicon protein concentrator (YM10 membrane). The volume of the protein solution was measured and the protein concentration was determined by the Bradford method (Bradford, 1976). [thioester- $\left.{ }^{13} \mathrm{C}=\mathrm{O}\right]-4-\mathrm{HBA}-\mathrm{CoA}$ was added in a quantity to equal two-thirds the concentration of enzyme. Ten milliliters of $5 \mathrm{mM} \mathrm{K}^{+}$-HEPES and $0.5 \mathrm{mM}$ DTT in $\mathrm{D}_{2} \mathrm{O}(\mathrm{pD} 7.5$ ) was added and the enzyme was further concentrated with the ligand present (in order to avoid precipitation of the enzyme) to $2 \mathrm{~mL}$. The addition of buffer and concentration of the protein solution was repeated three times. The enzyme solution was concentrated to a final concentration of $1.5 \mathrm{mM}$, without any significant loss of ligand. Enzyme samples either containing 4-HBA-CoA at natural isotope abundance or not containing 4-HBA-CoA were prepared in a similar fashion. The $\mathrm{pD}$ of all the NMR samples was adjusted to 7.5 by the addition of KOD and the final concentration of the buffer was approximately $5 \mathrm{mM} \mathrm{K}^{+}$-HEPES and $0.5 \mathrm{mM}$ DTT $\left(90-95 \% \mathrm{D}_{2} \mathrm{O}\right)$. The NMR spectra were measured at 125.77 MHz on a Bruker AM 500-MHz NMR spectrometer using the general protocol given in Jaffe and Markham (1987). The probe temperature was $25^{\circ} \mathrm{C}$. Chemical shifts are reported with respect to an external reference dioxane, which was assigned a chemical shift of $66.5 \mathrm{ppm}$. All protein and protein-ligand spectra were acquired in the ${ }^{13} \mathrm{C}$ protondecoupled mode with a $45^{\circ}$ pulse angle and a relaxation delay of $0.5 \mathrm{~s}$. Data were acquired every $1.5 \mathrm{~s}$. The spectra are a result of 24000 transients each. The NMR solutions (0.5$0.6 \mathrm{~mL}$ in $5-\mathrm{mm}$ quartz NMR tubes) typically contained 1.5 $\mathrm{mM}$ 4-CBA-CoA dehalogenase in $5 \mathrm{mM} \mathrm{K}^{+}$-HEPES and $0.5 \mathrm{mM}$ DTT, pD $7.5 \pm 0.1\left(90-95 \% \mathrm{D}_{2} \mathrm{O}\right)$, and varying concentrations of $\left[\right.$ thioester $\left.-{ }^{13} \mathrm{C}=\mathrm{O}\right]-4-\mathrm{HBA}-\mathrm{CoA}$. The sample enzyme activity and $\mathrm{pD}$ were checked before and after each experiment. 
Table 1: Steady-State Kinetic Constants and Substrate Analog (4-MeBA-CoA) and Product (4-HBA-CoA) Binding Constants Measured for Wild-Type and Mutant 4-CBA-CoA Dehalogenase ${ }^{a}$

\begin{tabular}{|c|c|c|c|c|c|c|}
\hline \multirow[b]{2}{*}{ enzyme } & \multicolumn{2}{|c|}{ 4-CBA-CoA } & \multicolumn{2}{|c|}{ 4-MeBA-CoA } & \multicolumn{2}{|c|}{ 4-HBA-CoA } \\
\hline & $k_{\text {cat }}\left(\mathrm{s}^{-1}\right)$ & $K_{\mathrm{m}}(\mu \mathrm{M})$ & $K_{\mathrm{d}}^{b}(\mu \mathrm{M})$ & $K_{1}^{c}(\mu \mathrm{M})$ & $K_{\mathrm{d}}^{b}(\mu \mathrm{M})$ & $K_{1}^{c}(\mu \mathrm{M})$ \\
\hline wild type & 0.6 & $3.7 \pm 0.3$ & $2.8 \pm 0.2$ & $4.2 \pm 0.5$ & 0.5 & $2.5 \pm 0.1$ \\
\hline D145A & & & 1.0 & & 0.1 & \\
\hline H90Q & & & 2.5 & & 0.7 & \\
\hline H81Q & & & 1.3 & & 0.6 & \\
\hline W89Y & & & & & $50-100$ & \\
\hline G114A & 0.002 & $100 \pm 10$ & & & $50-100$ & \\
\hline W137F & 0.01 & $17 \pm 2$ & 0.6 & $2.6 \pm 0.2$ & 1.8 & $7.9 \pm 0.8$ \\
\hline W89F & 0.03 & $22 \pm 4$ & & $35 \pm 3$ & $2.6 \pm 0.5$ & $4.7 \pm 0.5$ \\
\hline F64L & 0.1 & $4.5 \pm 0.4$ & $31 \pm 4$ & $7.3 \pm 0.7$ & 0.4 & $2.2 \pm 0.2$ \\
\hline F82L & 0.09 & $6.6 \pm 0.4$ & & $9 \pm 1$ & & $2.0 \pm 0.1$ \\
\hline
\end{tabular}

${ }^{a}$ Measurements were made at $\mathrm{pH} 7.5$ in $50 \mathrm{mM} \mathrm{K}{ }^{+}$-HEPES buffer at $25{ }^{\circ} \mathrm{C}$. See Materials and Methods for details. ${ }^{b} K_{\mathrm{d}}$ measured from UV-visible difference spectral titration experiments. See Materials and Methods for details. ${ }^{c} K_{\mathrm{i}}$ measured from competitive inhibition experiments. See Materials and Methods for details.

Stopped-Flow Absorption Kinetic Experiments. A DX.17 MV stopped-flow spectrometer (Applied Photophysics, Leatherhead, U.K.) having a dead time of $2 \mathrm{~ms}$ was used for measurement of association and conversion rate constants of W137F mutant and wild-type 4-CBA-CoA dehalogenase with 4-HBA-CoA. The light source was a $150-\mathrm{W}$ xenon lamp (1-mm slit width). The drive syringes were driven by a pneumatic actuator operated by compressed nitrogen (pressure from 5 to 8 bar). Stock solutions of ligand and enzyme were diluted to $48 \mu \mathrm{M}$ with $50 \mathrm{mM} \mathrm{K}{ }^{+}$-HEPES buffer at $\mathrm{pH} 7.5$ prior to reaction $\left(22^{\circ} \mathrm{C}\right)$ initiated by mixing $50-\mu \mathrm{L}$ aliquots. Solution absorbance was monitored at 330 and at $373 \mathrm{~nm}$. Data acquisition and processing were controlled by a 32-bit processor Archimedes workstation, which was also used for subsequent nonlinear regression analysis of the traces. In each experiment, 400 pairs of data were recorded. Kinetic data were analyzed with a singleexponential equation.

\section{RESULTS}

The change in the distribution in $\pi$-electron density within the benzoyl ring of the substrate and product ligand that occurs upon binding to the active site of 4-CBA-CoA dehalogenase, is evidenced by the UV, Raman, and ${ }^{13} \mathrm{C} N M R$ spectral properties of the bound and unbound forms of 4-MeBA-CoA (substrate analog) and 4-HBA-CoA (product). Briefly, we have reported (Taylor et al., 1995) that (1) the $\lambda_{\max }$ for the benzoyl moiety of 4-MeBA-CoA undergoes a red shift to $302 \mathrm{~nm}$ and that $\lambda_{\max }$ of the benzoyl moiety of 4-HBA-CoA undergoes a red shift to 330 and $373 \mathrm{~nm}$, upon ligand complexation with the enzyme, (2) the ${ }^{13} \mathrm{C}$ NMR signal from the benzoyl $\mathrm{C}=\mathrm{O}$ in $\left[\right.$ thioester $\left.-{ }^{13} \mathrm{C}=\mathrm{O}\right]-4-\mathrm{HBA}$ CoA is shifted 2.8 ppm downfield upon enzyme complexation, and (3) the Raman bands corresponding to the benzoyl $\mathrm{C}=\mathrm{O}$ stretch, in-plane phenyl $\mathrm{C}-\mathrm{H}$ stretches, and benzene ring modes $8 \mathrm{a}$ and $8 \mathrm{~b}$ observed for $4-\mathrm{HBA}-\mathrm{CoA}$ and 4-MeBA-CoA in buffer are dramatically altered upon enzyme complexation. The studies presented below constitute a more in-depth examination of the UV-visible spectral perturbations resulting from ligand-enzyme binding. These measurements are, along with steady-state kinetic measurements and ${ }^{13} \mathrm{C}$ NMR spectral measurements of bound $\left[\right.$ thioester ${ }^{-13} \mathrm{C}=\mathrm{O}$ ]4-HBA-CoA, extended to a series of dehalogenase activesite mutants for the purpose of identifying the active-site residues (Figure 1) that play an essential role in the polarization of the ligand benzoyl ring.
Preparation and Kinetic Characterization of 4-CBA-CoA Dehalogenase Mutants. The 4-CBA-CoA dehalogenase mutant genes used for the expression of the mutant proteins were constructed in this study (G114P, G114A, W89F, W89Y, F64L, and F82L), or in an earlier study (D145A, H81Q, H90Q, and W137F; Yang et al., 1996), using the clone of the wild-type gene (Chang et al., 1992) in conjunction with PCR techniques. With the exception of the G114P mutant (which we were unable to isolate), each of the mutant enzymes proved to be stable to purification and was obtained in a homogeneous state as judged by SDS-PAGE analysis. The steady-state kinetic properties of the mutants were measured using initial velocity techniques. The $k_{\mathrm{cat}}$ and $K_{\mathrm{m}}$ values, determined for the dehalogenation of 4-CBA-CoA in $50 \mathrm{mM} \mathrm{K}{ }^{+}$-HEPES buffer $\left(\mathrm{pH} 7.5,25^{\circ} \mathrm{C}\right)$, are listed in Table 1. The inhibition constants $\left(K_{\mathrm{i}}\right)$ of $4-\mathrm{MeBA}-\mathrm{CoA}$ and 4-HBA-CoA as competitive inhibitors vs 4-CBA-CoA were measured with the wild-type enzyme and the mutants W89F, F64L, F82L, and W137F. These values are reported in Table 1 along with the dissociation constants $\left(K_{\mathrm{d}}\right)$ measured for the enzyme-ligand complexes using UV-visible spectral absorption techniques (described in the following section).

Substrate Turnover. The D145A, H90Q, and H81Q dehalogenase mutants bind 4-MeBa-CoA and 4-HBA-CoA tightly $\left(K_{\mathrm{d}}<5 \mu \mathrm{M}\right.$; Table 1$)$ but are unable to catalyze steady-state turnover (Yang et al., 1996). The inactivity of D145A and H90Q is consistent with the respective D145 and $\mathrm{H} 90$ roles in catalysis as nucleophile and general base (Scheme 1, Figure 1). Because H81 is somewhat removed from the actual site of substrate binding/catalysis [it is located $8.8 \AA$ from the benzoyl ring C(4)], it is presently unclear why its mutation to Gln results in the loss of activity.

The W137 residue is one of the several aromatic residues (W137, W89, F64, and F64) shown in Figure 1 which, together, form the hydrophobic binding pocket for the substrate benzoyl ring. In addition to this function, the W137 side chain is also positioned in the active site for interaction, via the indole NH, with Asp145 (Scheme 1, Figure 1). In the previous study we had measured the turnover rate for the W137F mutant as $0.002 \mathrm{~s}^{-1}$, 300-fold slower than that of the wild-type enzyme (Yang et al., 1996). In the present study, a more active preparation of the W137F mutant was obtained which gave a turnover rate of $0.01 \mathrm{~s}^{-1}$, a rate which is only 60 -fold slower than that of wild type.

Replacement of the two Phe residues (64 and 82) that contribute to the hydrophobic binding site with Leu decreases 
turnover only 6-fold in each mutant. Replacement of Trp89, on the other hand, with Phe results in a 20-fold drop in turnover rate. Replacement of W89 with Tyr reduces catalysis (>1000-fold) below our detection limit.

G114, the residue which occupies the N-terminal position of the 114-121 $\alpha$-helix is positioned to donate it's amide $\mathrm{NH}$ for H-bond formation with the ligand benzoyl $\mathrm{C}=\mathrm{O}$. Mutation of G114 to Pro resulted in an unstable enzyme. Mutation of G114 to an Ala results in a relatively stable, but substantially functionally impaired, catalyst (300-fold less active than wild-type enzyme).

Ligand Binding. The $K_{\mathrm{m}}, K_{\mathrm{i}}$, and $K_{\mathrm{d}}$ (from the spectral titrations described below) values serve as independently derived estimates of enzyme-ligand binding affinity. The $K_{\mathrm{m}}$ and $K_{\mathrm{i}}$ determinations were made using the enzyme at comparatively low concentration $(<3 \mu \mathrm{M})$ and ligand in excess. The $K_{\mathrm{d}}$ measurements were made at high enzyme concentration $(10-25 \mu \mathrm{M})$ using the ligand at concentrations that range from below to above the enzyme concentration. The $K_{\mathrm{d}}$ measurements involved prolonged incubation of ligand with enzyme (20 min; allowing any slow, ligandinduced conformational changes which might occur to reach equilibrium) while the $K_{\mathrm{m}}$ and $K_{\mathrm{i}}$ measurements did not. Finally, we point out that the $K_{\mathrm{m}}$, unlike the $K_{\mathrm{i}}$ and $K_{\mathrm{d}}$, is not a true dissociation constant. Of the three constants, the $K_{\mathrm{i}}$ is, in our judgment, the most accurate indicator of enzyme-ligand binding affinity. However, for the inactive mutants the spectral titration-based $K_{\mathrm{d}}$ determination is the only method by which ligand binding can be assessed.

The $K_{\mathrm{i}}$ measured for CoA with the wild-type dehalogenase is $140 \mu \mathrm{M}$ (Liang et al., 1993), whereas the $K_{\mathrm{i}}$ and $K_{\mathrm{d}}$ values obtained for 4-MeBA-CoA and 4-HBA-CoA and the $K_{\mathrm{m}}$ value obtained for 4-CBA-CoA range below $5 \mu \mathrm{M}$ (Table 1). It is thus apparent that the contribution of the benzoyl ring to binding is not large but is nevertheless detectable. The benzoyl ring and CoA binding sites are located in separate clefts on the enzyme (Benning et al., 1996). Mutations made at the benzoyl ring binding site are not likely to disrupt $\mathrm{CoA}-$ enzyme binding interactions at the $\mathrm{CoA}$ site. Thus, mutations made at the benzoyl site which result in an increase of the binding constant to a value approximating that of CoA are likely to have interfered with the binding of the benzoyl moiety at the reaction site. With this in mind we note that the values of the ligand binding constants $\left(K_{\mathrm{d}}\right)$ obtained for the D145A, H90Q, and H81Q mutants are below $5 \mu \mathrm{M}$. Thus, benzoyl ring binding in these mutants remains intact, despite the loss of catalytic activity.

The W137F, W89F, F64L, and F82L mutants appear to have suffered some decrease in ligand benzoyl ring binding capacity. All binding constants are significantly larger than those obtained for the wild-type enzyme but do not exceed $10 \mu \mathrm{M}$ (with the notable exception of the W89F-4-MeBACoA $K_{\mathrm{i}}$ value of $\left.35 \mu \mathrm{M}\right)$. While the replacements of the Trp side chains with Phe side chains and Phe side chains with the aliphatic Leu side chains conserved the hydrophobicity of the binding pocket, they have no doubt altered the side-chain-ligand packing interactions.

The G114A and W89Y mutants provide clear examples of mutations which dramatically disrupt the binding of the ligand benzoyl moiety. This is indicated for the G114A mutant by the large $K_{\mathrm{m}}$ value $(100 \mu \mathrm{M})$ obtained for 4-CBA$\mathrm{CoA}$ and by the results from the spectral titrations with 4-MeBA-CoA and 4-HBA-CoA. The 4-HBA-CoA titration
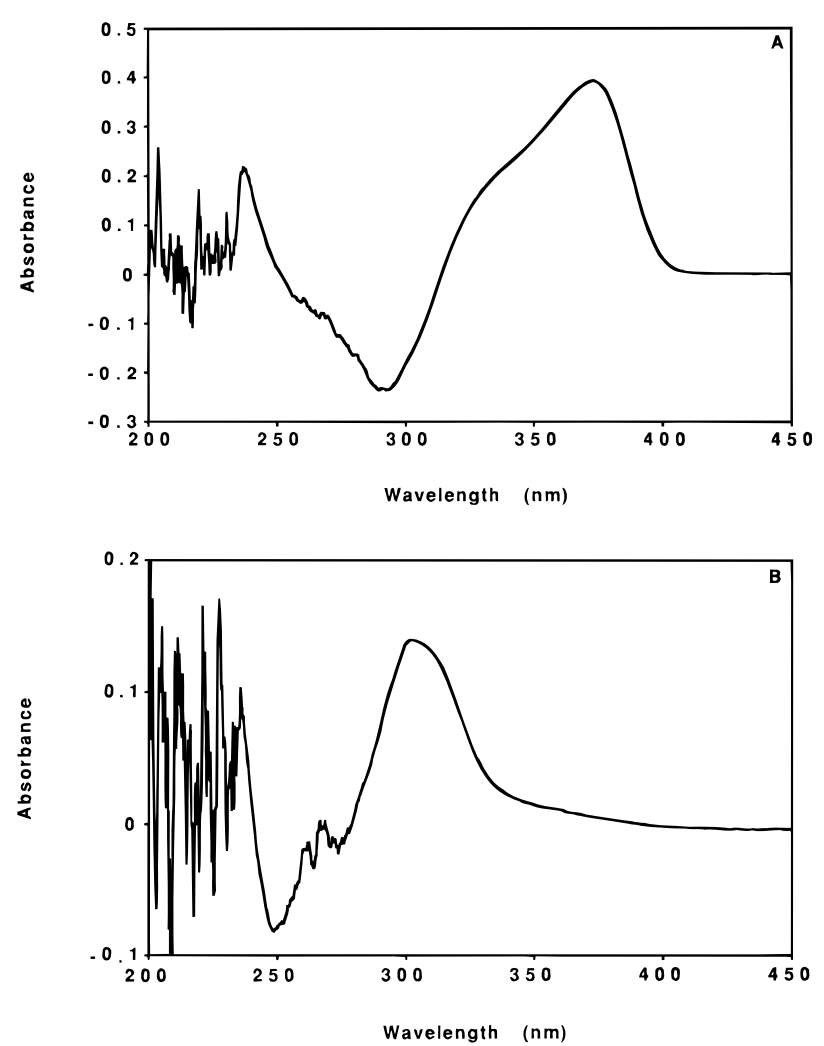

FIGURE 2: UV-Visible difference spectrum of the wild-type dehalogenase complex of (A) 4-HBA-CoA or (B) 4-MeBA-CoA. The spectrum measured for $0.5 \mathrm{~mL}$ of $200 \mu \mathrm{M}$ ligand in $50 \mathrm{mM}$ $\mathrm{K}^{+}$-HEPES (pH 7.5) (compartment 1 ) and $0.5 \mathrm{~mL}$ of $50 \mu \mathrm{M}$ wildtype 4-CBA-CoA dehalogenase in $50 \mathrm{mM} \mathrm{K}^{+}$-HEPES ( $\mathrm{pH} 7.5$ ) (compartment 2) contained in a $1-\mathrm{mL}$ quartz tandem cell was subtracted from the spectrum measured after the two compartments were mixed.

provided a rough estimate of the $K_{\mathrm{d}}$ value within the range of $50-100 \mu \mathrm{M}$. The 4-MeBA-CoA titration is not sufficiently sensitive to be used to measure $K_{\mathrm{d}}$ values this large, and therefore we do not know what this value is, only that it probably exceeds $50 \mu \mathrm{M}$. A similar result was obtained with the W89Y mutant for which an estimate of the 4-HBACoA $K_{\mathrm{d}}$ value in the range of $50-100 \mu \mathrm{M}$ could be made but no estimate could be made for the 4-MeBA-CoA $K_{\mathrm{d}}$ value. Neither mutant was amenable to a steady-state $K_{\mathrm{i}}$ measurement.

UV-Visible Difference Spectra of 4-MeBA-CoA and 4-HBA-CoA Bound to the Active Site of Wild-Type 4-CBACoA Dehalogenase. The UV-visible difference spectra of the wild-type enzyme-4-HBA-CoA and enzyme-4-MeBACoA complexes were measured using a two-chambered tandem cell, initially containing $0.5 \mathrm{~mL}$ of $50 \mu \mathrm{M}$ enzyme in $50 \mathrm{mM} \mathrm{K}^{+}$-HEPES (pH 7.5) in one chamber and $0.5 \mathrm{~mL}$ of $200 \mu \mathrm{M}$ ligand in $50 \mathrm{mM} \mathrm{K} \mathrm{K}^{+}$-HEPES (pH 7.5) in the other. This spectrum was then subtracted from the spectrum obtained after the contents of the two chambers were mixed (producing a solution of $100 \mu \mathrm{M}$ ligand and $25 \mu \mathrm{M}$ enzyme in $50 \mathrm{mM} \mathrm{K} \mathrm{K}^{+}$-HEPES, $\mathrm{pH}$ 7.5). On the basis of the measured inhibition constants of 4-HBA-CoA and 4-MeBACoA with wild-type dehalogenase $\left(K_{\mathrm{i}}=3 \mu \mathrm{M}\right.$ and $4 \mu \mathrm{M}$, respectively; Table 1) we judge that the enzyme is saturated with ligand in the mixed solution.

The difference spectrum of the 4-HBA-CoA complex, shown in Figure 2A, is characterized by a trough at $290 \mathrm{~nm}$ and two overlapping peaks roughly centered at $330 \mathrm{~nm}(\epsilon$ 

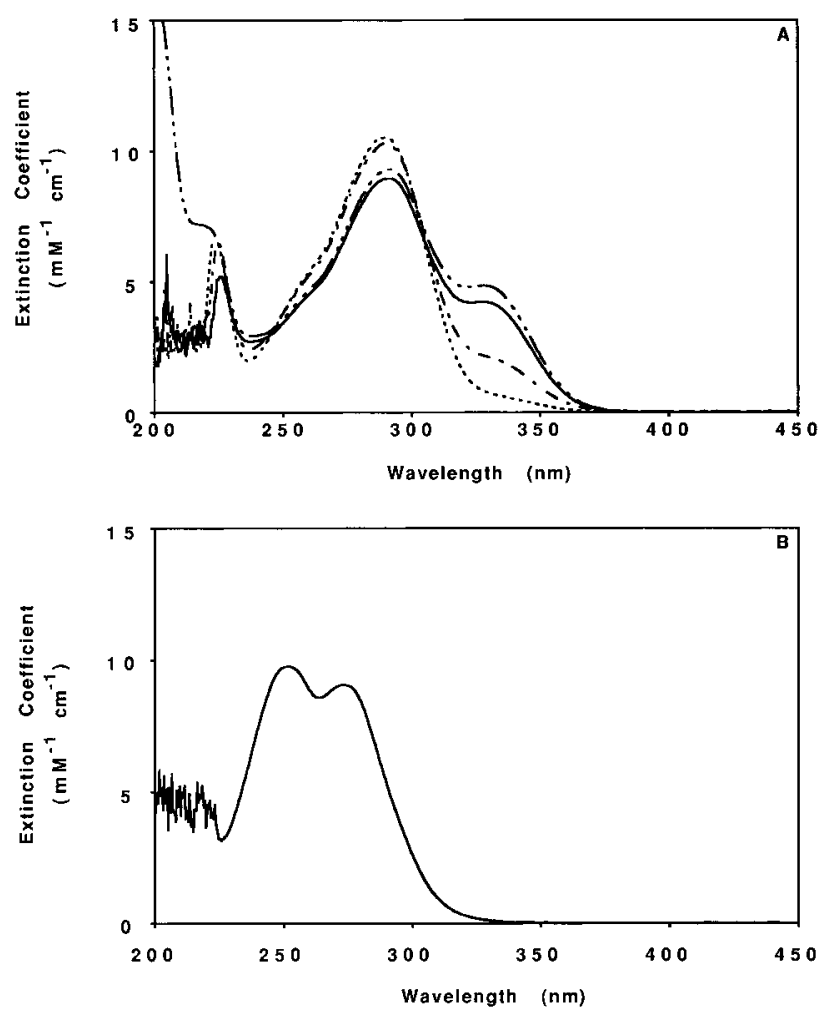

FIGURE 3: UV-Visible spectrum of (A) 4-HBA-pantetheine in water $(-\cdots-)$, in $50 \mathrm{mM} \mathrm{K} \mathrm{K}^{+}$-HEPES, pH $7.5(-)$ or $\mathrm{pH} 7.0$ $(-\cdot-)$, and in $50 \mathrm{mM} \mathrm{K}{ }^{+}-\mathrm{Mes}$, pH $6.5(\cdots)$ and of (B) 4-CBApantetheine in $50 \mathrm{mM} \mathrm{K}{ }^{+}$-HEPES, pH 7.5 .

$\left.=5 \mathrm{mM}^{-1} \mathrm{~cm}^{-1}\right)$ and $373 \mathrm{~nm}\left(\epsilon=17 \mathrm{mM}^{-1} \mathrm{~cm}^{-1}\right)$. The UV-visible spectrum of 4-HBA-pantetheine in $\mathrm{pH} 6.5$ buffer (Figure 3A) shows a broad absorption peak with a maximum at $290 \mathrm{~nm}\left(\epsilon=9.0 \mathrm{mM}^{-1} \mathrm{~cm}^{-1}\right)$ (Taylor, 1996). A small shoulder at $c a .260 \mathrm{~nm}$ is suggestive of a minor benzoyl absorption band centered at a shorter wavelength. The spectrum of 4-HBA-pantetheine measured at $\mathrm{pH} 7.5$ shows an additional shoulder at $330 \mathrm{~nm}$, contributed by a small quantity of phenolate form present (for 4-HBA-CoA the $\mathrm{p} K_{\mathrm{a}}$ $=8.6$ and the $\epsilon=24 \mathrm{mM}^{-1} \mathrm{~cm}^{-1}$ at the $330-\mathrm{nm} \lambda_{\max }$; Mieyal et al., 1974). On the basis of the spectral properties of the 4-HBA-pantetheine, we estimate that the $\lambda_{\max }$ of the benzoyl moiety in the 4-HBA-CoA must be at ca. $290 \mathrm{~nm}$. The 290nm trough and the 330- and 373-nm peaks observed in the difference spectrum of the 4-HBA-CoA complex appear then, to result from a large red shift in the $290-\mathrm{nm}$ benozyl ring absorption band. The dual absorptions at 330 and $373 \mathrm{~nm}$ do not arise from split $\pi-\pi^{*}$ transitions nor do they derive from the phenol vs phenolic forms of the hydroxybenzoyl ligand [see Taylor et al. (1995)]. They appear, instead, to result from two distinct conformations of the active site and/ or bound benzoyl ring (as shown by the stopped-flow UVvisible absorption and ${ }^{13} \mathrm{C}$ NMR spectral studies described below). Further consideration of the two forms is provided in the following sections.

The difference spectrum of the 4-MeBA-CoA-dehalogenase complex, shown in Figure $2 \mathrm{~B}$, is characterized by an asymmetric trough spanning 240-290 nm. The peak spans $290-330 \mathrm{~nm}$ and has a $\lambda_{\max }$ at $302 \mathrm{~nm}$. The spectrum of the $S$-ethyl thioester of 4-MeBA in $50 \mathrm{mM} \mathrm{K}^{+}$-HEPES ( $\mathrm{pH} 7.5)$ shows two overlapping peaks centered at $257(\epsilon=$ $4 \mathrm{mM}^{-1} \mathrm{~cm}^{-1}$ ) and $273 \mathrm{~nm}\left(\epsilon=3 \mathrm{mM}^{-1} \mathrm{~cm}^{-1}\right.$ ) (Clarkson and Carey, unpublished data). Likewise, the spectrum of
4-CBA-pantetheine shows two overlapping peaks, one with a $\lambda_{\max }$ at $253 \mathrm{~nm}\left(\epsilon=9.7 \mathrm{mM}^{-1} \mathrm{~cm}^{-1}\right)$ and the other with a $\lambda_{\max }$ at $274 \mathrm{~nm}\left(\epsilon=9.2 \mathrm{mM}^{-1} \mathrm{~cm}^{-1}\right)$ (Figure $\left.3 \mathrm{~B}\right)$. Thus, the benzoyl moieties of 4-methyl and 4-chlorobenzoyl thioesters give rise to two (split $\pi-\pi^{*}$ ) absorption bands which, in the case of the CoA adducts, are overlaid by the intense adenine absorption band $\left(17 \mathrm{mM}^{-1} \mathrm{~cm}^{-1}\right)$ at $260 \mathrm{~nm}$. The 302-nm peak observed in the difference spectrum of the 4-MeBA-CoA-dehalogenase complex therefore appears to be the result of a $28-45-\mathrm{nm}$ red shift in the benzoyl absorption bands.

We now present the spectra generated from a series of control experiments carried out to ensure that the difference spectra of the 4-HBA-CoA- and 4-MeBA-CoA-dehalogenase complexes (shown in Figure 2, panels $\mathrm{A}$ and $\mathrm{B}$, respectively) reflect the change in absorbance of the ligand benzoyl ring, passing from buffer solution to the active site of the enzyme, and nothing else. First, difference spectra were measured for the undiluted vs diluted samples of enzyme and ligand. Tandem cells were set up with $0.5 \mathrm{~mL}$ of $50 \mu \mathrm{M}$ wild-type dehalogenase in one chamber and 0.5 $\mathrm{mL}$ of buffer in the other or $0.5 \mathrm{~mL}$ of $200 \mu \mathrm{M}$ ligand in one chamber and $0.5 \mathrm{~mL}$ of buffer in the other. The spectra were recorded and then the contents of the two chambers were mixed. The spectra of the diluted (mixed) ligands and enzyme are overlaid on the initial spectra in Figure 4A,C,E. The difference spectra of the unmixed vs mixed solutions, provided in Figure 4B,D,F, are essentially featureless. We thus rule out possible artifacts arising from solution mixing and enzyme/ligand dilution.

Next, the spectra of the contents of the tandem cells set up with $50 \mu \mathrm{M}$ wild-type dehalogenase $\left(50 \mathrm{mM} \mathrm{K} \mathrm{K}^{+}\right.$-HEPES, $\mathrm{pH} 7.5)$ in one compartment and an equal volume of 200 $\mu \mathrm{M}$ ligand (50 $\mathrm{mM} \mathrm{K} \mathrm{K}^{+}$-HEPES, $\mathrm{pH} 7.5$ ) in the other, were recorded before and after the contents of the two compartments were mixed. These two sets of spectra are shown as overlays in Figure 5A,D. These spectra allow us to observe the extent to which the ligand and the enzyme contribute to the composite spectra and, by comparison to the difference spectra shown in Figure 2A,B, to determine exactly what percent of the original spectra the difference spectra represent. (The $25 \mu \mathrm{M}$ ligand complexed to enzyme contributes a maximum absorption of $c a$. 0.2 from the benzoyl ring moiety). As can be seen, the difference spectra represent comparatively large changes in absorption in regions outside the 300-nm absorption boundary but very small changes within that boundary. In the latter case, the magnitude of the error introduced by the subtraction process was cause for concern. In order to evaluate the extent of the error introduced by the spectral subtraction, it was repeated using spectra measured with $50 \mu \mathrm{M}$ ligand in the chamber of the tandem cell instead of $200 \mu \mathrm{M}$ ligand (under these conditions the concentration of bound ligand is roughly $24 \mu \mathrm{M}$ and the concentration of unbound ligand, roughly $1 \mu \mathrm{M}$ once the contents of the two chambers are mixed). ${ }^{2}$ The spectral overlays are shown in Figure 5B,E, whereas the corresponding difference spectra are shown in Figure 5C,F. Comparison of the two sets of difference spectra obtained using 200 $\mu \mathrm{M}$ ligand (Figure 2A,B) with those obtained using $50 \mu \mathrm{M}$ ligand (Figure 5C,F) reveals minimal error introduced by the subtraction of large absorbancies to yield small differences. Thus, we rule out subtraction error as a possible 

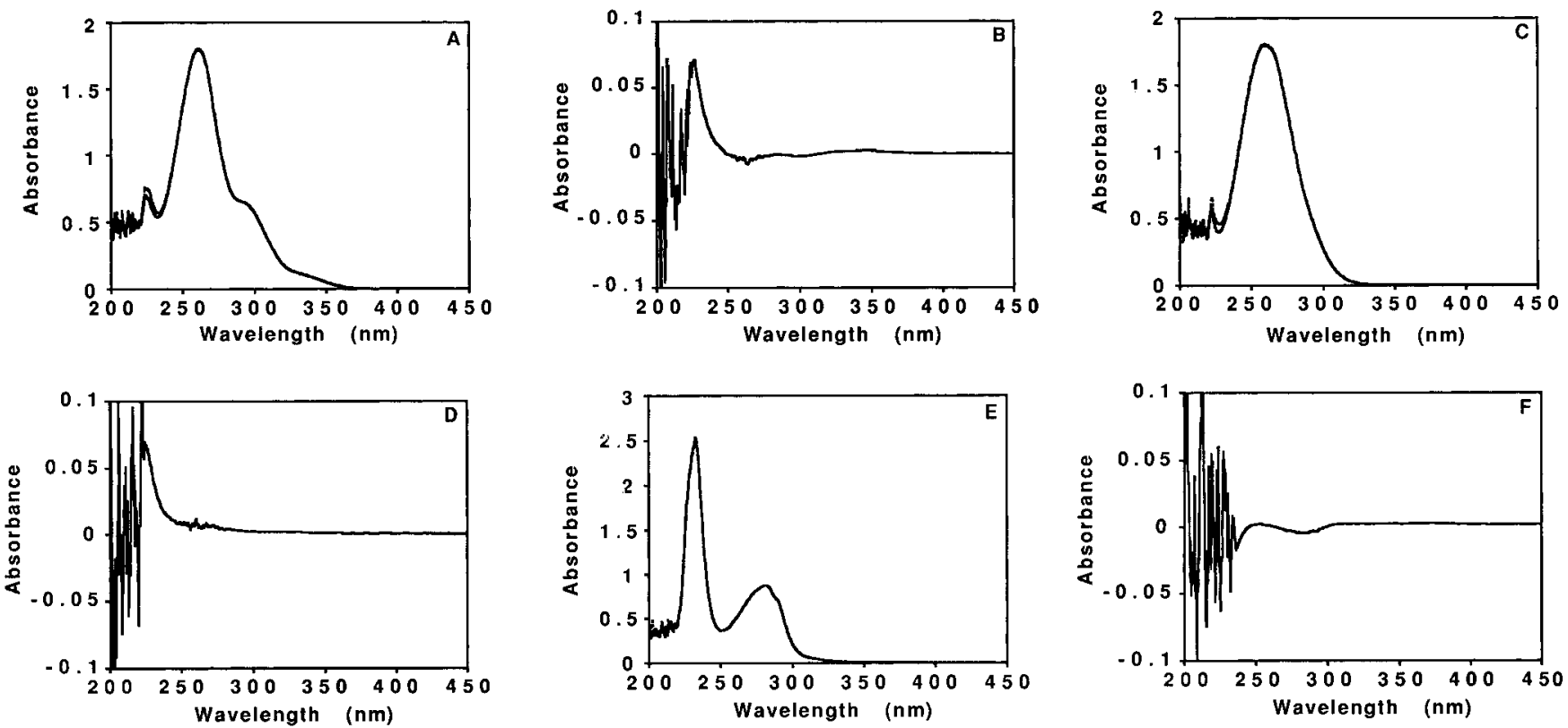

FIGURE 4: UV-Visible spectra and difference spectra measured for the dilution of ligand or 4-CBA-CoA dehalogenase into buffer using a 1-mL quartz tandem cell. (A) Compartment $1,0.5 \mathrm{~mL}$ of $200 \mu \mathrm{M} 4-\mathrm{HBA}-\mathrm{CoA}$, and compartment $2,0.5 \mathrm{~mL}$ of $50 \mathrm{mM} \mathrm{K}{ }^{+}$-HEPES (pH 7.5), before (-) and after ( $\cdots$ ) mixing; (B) difference spectrum from panel A; (C) compartment 1, $0.5 \mathrm{~mL}$ of $200 \mu \mathrm{M} 4-\mathrm{MeBA}-\mathrm{CoA}$, and compartment 2, $0.5 \mathrm{~mL}$ of $50 \mathrm{mM} \mathrm{K}{ }^{+}$-HEPES (pH 7.5), before (-) and after ( $\cdots$ ) mixing; (D) difference spectrum from panel C; (E) compartment 1, $0.5 \mathrm{~mL}$ of $50 \mathrm{mM} \mathrm{K}{ }^{+}$-HEPES (pH 7.5), and compartment $2,0.5 \mathrm{~mL}$ of $50 \mu \mathrm{M}$ wild-type dehalogenase, before ( - ) and after $(\cdots)$ mixing; (F) difference spectrum from panel $\mathrm{E}$.

artifact contributing to the observed difference spectra of the enzyme-ligand complexes.

Finally, we examined the possible contribution of ligandinduced changes in the enzyme absorption spectrum to the difference spectra measured for the 4-HBA-CoA- and 4-MeBA-CoA-dehalogenase complexes. As can be seen from the absorbance spectrum of the wild-type dehalogenase shown in Figure 4E, the absorption by the Trp residues extends out beyond $300 \mathrm{~nm}$. In the active site of the enzyme, two Phe residues (Phe64 and Phe82) and two Trp residues (Trp89 and Trp137) encircle the benzoyl ring of the 4-HBACoA ligand (Benning et al., 1996) (see Figure 1). Ligand binding would no doubt lead to desolvation and reorientation of the aromatic rings and this, in turn, may lead to an absorbance shift. The absorption bands centered at 330 and $373 \mathrm{~nm}$ for the wild-type dehalogenase-4-HBA-CoA complex (Figure 2A) occur at wavelengths too long to originate in the enzyme Trp residues. In fact, the absence of these absorption bands in the difference spectrum of the enzyme4-MeBA-CoA complex is evidence that they originate from the (comparatively more polarizable) hydroxybenzoyl moiety of the 4-HBA-CoA ligand.

The 302-nm absorption band observed in the difference spectrum of the dehalogenase-4-MeBA-CoA complex (Figure $2 \mathrm{~B}$ ), on the other hand, overlaps with the region of the enzyme Trp absorption (Figure 4E). Thus, the spectral shift which takes place upon association of the enzyme and the 4-MeBA-CoA could, in principle, originate in the enzyme

\footnotetext{
${ }^{2}$ The high ligand concentration was used to maximize the concentration of enzyme-ligand complex. For wild-type enzyme and most of the mutant enzymes, where ligand binding is tight (see Table 1), a high ligand concentration is not necessary to saturate the enzyme. However, in some of the mutants ligand binding is comparatively weak and, thus, a high ligand concentration must be employed. Because we intended to make a direct comparison between the difference spectra of the mutant enzyme-ligand complexes, all spectral measurements were carried out using the same enzyme-ligand concentrations.
}

rather than the benzoyl moiety of the ligand. To test for such a shift in the enzyme absorption spectrum, structural analogs of the 4-MeBA-CoA ligand, having unique spectral properties, were employed to occupy the enzyme active site while the difference spectrum of the complexed and uncomplexed enzyme was measured. Trans-2-methyl-2-butenoylCoA (tiglyl-CoA) binds tightly to the dehalogenase $\left(K_{\mathrm{i}}=\right.$ $1.8 \mu \mathrm{M})$. In buffer, the tiglyl-CoA enoyl-thioester moiety is, on the basis of the reported spectrum of the $S$-crotonyl$N$-acetylcysteamine $\left(\lambda_{\max }=225 \mathrm{~nm}, \epsilon=10.6 \mathrm{mM}^{-1} \mathrm{~cm}^{-1}\right.$, and $263 \mathrm{~nm}, \epsilon=6.5 \mathrm{mM}^{-1} \mathrm{~cm}^{-1}$ ) (Lynen, 1969), expected to show an absorption band centered at $c a .260 \mathrm{~nm}$. The difference spectrum of the wild-type dehalogenase-tiglylCoA complex (formed in a mixture of $25 \mu \mathrm{M}$ dehalogenase and $100 \mu \mathrm{M}$ tiglyl-CoA), shown in Figure 6A, is characterized by a trough at $260 \mathrm{~nm}$ and a peak at $280 \mathrm{~nm}$. This difference spectrum is distinctly different from that measured for the wild-type dehalogenase-4-MeBA-CoA complex (250-nm trough, 302-nm peak; Figure 2B). The second analog examined, propionyl-CoA $\left(K_{\mathrm{i}}=80 \mu \mathrm{M}\right)$, does not contain an enoyl-thioester chromophore, and thus, no spectral shift is expected to result from the ligand upon binding to the enzyme. The difference spectrum of the wild-type dehalogenase-propionyl-CoA complex (formed in a mixture of $25 \mu \mathrm{M}$ enzyme and $200 \mu \mathrm{M}$ propionyl-CoA), provided in Figure 6B, shows little absorption in the 300-nm region. Finally, phenylacetyl-CoA ( $K_{\mathrm{i}}=110 \mu \mathrm{M}$; Liu et al., 1995), whose phenyl ring $\pi$-electrons are not in conjugation with those of the thioester moiety, was used to complex with the enzyme. The difference spectrum measured for the wildtype 4-CBA-CoA dehalogenase-phenylacetyl-CoA complex (formed in a mixture of $25 \mu \mathrm{M}$ enzyme and $200 \mu \mathrm{M}$ phenylacetyl-CoA) and shown in Figure 6C, is similar to that observed with the dehalogenase-propionyl-CoA complex in that it reveals little absorption in the 300-nm region. Thus, we conclude that the $302-\mathrm{nm}$ absorption peak observed 

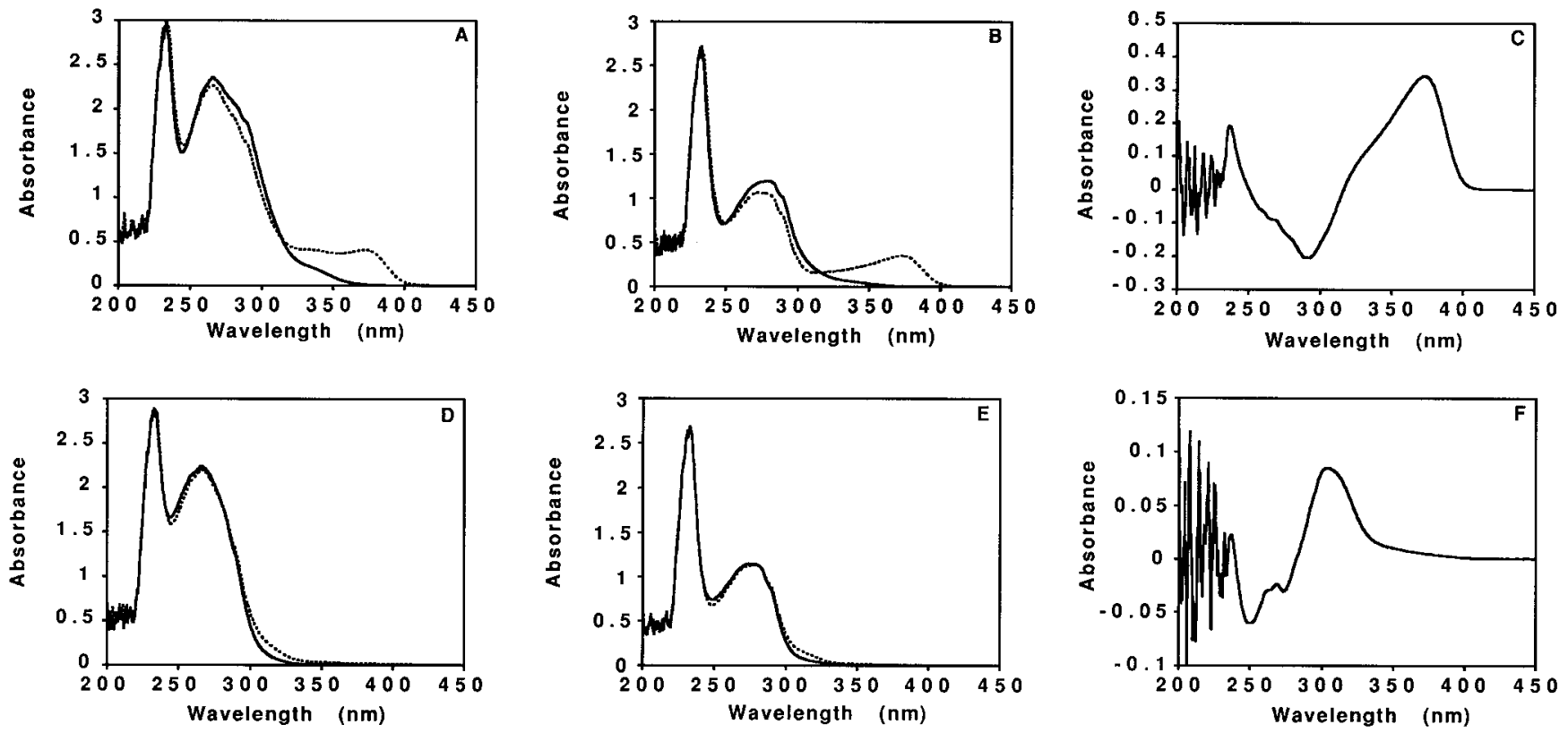

FIGURE 5: UV-Visible spectra and difference spectra measured for wild-type 4-CBA-CoA dehalogenase and ligand (both in $50 \mathrm{mM} \mathrm{K}^{+}$HEPES, pH 7.5) contained in separate compartments and mixed within both compartments of the 1-mL quartz tandem cell. (A) Compartment $1,0.5 \mathrm{~mL}$ of $200 \mu \mathrm{M} 4-\mathrm{HBA}-\mathrm{CoA}$, and compartment $2,0.5 \mathrm{~mL}$ of $50 \mu \mathrm{M}$ wild-type dehalogenase, before (-) and after ( $\cdots)$ mixing; (B) compartment $1,0.5 \mathrm{~mL}$ of $50 \mu \mathrm{M}$ 4-HBA-CoA, and compartment $2,0.5 \mathrm{~mL}$ of $50 \mu \mathrm{M}$ wild-type dehalogenase, before (-) and after $(\cdots)$ mixing; (C) difference spectrum from panel B; (D) compartment 1, $0.5 \mathrm{~mL}$ of $200 \mu \mathrm{M}$ 4-MeBA-CoA, and compartment $2,50 \mu \mathrm{M}$ wildtype dehalogenase, before (-) and after ( $\cdots$ ) mixing; (E) compartment $1,0.5 \mathrm{~mL}$ of $50 \mu \mathrm{M} 4-\mathrm{MeBA}-\mathrm{CoA}$, and compartment $2,50 \mu \mathrm{M}$ wild-type dehalogenase, before (-) and after ( $\cdots)$ mixing; (F) difference spectrum from panel E.
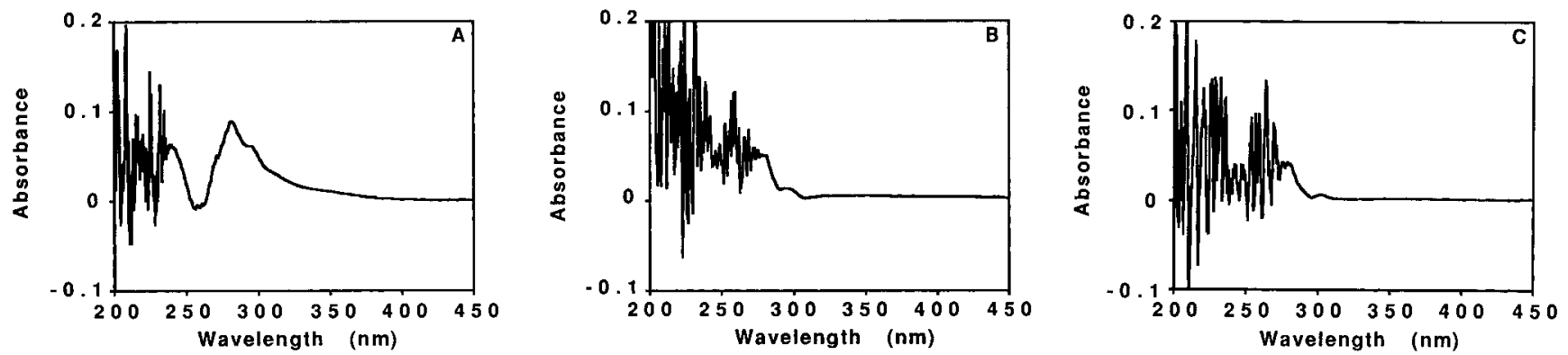

FIGURE 6: UV-Visible difference spectrum of the wild-type 4-CBA-CoA dehalogenase complex with tiglyl-CoA (A), propionyl-CoA (B), or phenylacetyl-CoA (C). The spectrum measured for $0.5 \mathrm{~mL}$ of $200 \mu \mathrm{M}$ tiglyl-CoA or $400 \mu \mathrm{M}$ propionyl-CoA or $400 \mu \mathrm{M}$ phenylacetyl-

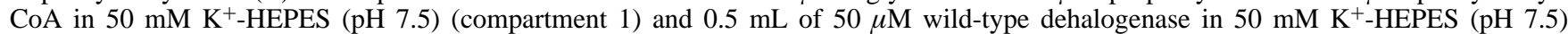
(compartment 2) contained in a 1-mL quartz tandem cell was subtracted from the spectrum measured after the two compartments were mixed.

in the difference spectrum of the dehalogenase-4-MeBACoA complex arises from a shift in the absorption band originating from the ligand benzoyl moiety.

UV-Visible Difference Spectra of 4-MeBA-CoA and 4-HBA-CoA Bound to the Active Sites of 4-CBA-CoA Dehalogenase Active-Site Mutants. The UV-visible difference spectra of 4-HBA-CoA and 4-MeBA-CoA complexes of dehalogenase active-site mutants were measured under the same conditions $(25 \mu \mathrm{M}$ enzyme and $100 \mu \mathrm{M}$ ligand in the final solution) described for the measurements made with the wild-type enzyme. The difference spectra are shown in Figure 7. In the case of the 4-HBA-CoA complexes of the F64L, F82L, and W137F dehalogenase mutants, absorption peaks centered at 330 and $373 \mathrm{~nm}$ are observed, similar to what is seen for the 4-HBA-CoA complex of the wild-type enzyme. The 4-HBA-CoA complexes of the W89F, W89Y, H90Q, H81Q, and G114A dehalogenase mutants, on the other hand, show a single absorption peak centered at 330 nm. The 4-HBA-CoA-D145A dehalogenase complex is unique in that it shows three absorption peaks of increasing height centered at 330, 373, and $400 \mathrm{~nm}$.
Ligand binding constants were measured by carrying out titrations of the enzymes with 4-HBA-CoA monitored at 330 or $373 \mathrm{~nm}$ (400 nm in the case of the D145A mutant). For all but two of the mutants (G114A and W89Y), the 4-HBACoA ligand binding is tight, yielding what appear to be welldefined titration curves (data not shown). The $K_{\mathrm{d}}$ values were extracted from the titration curves using standard curvefitting procedures (see Materials and Methods). In cases where binding is exceptionally tight $\left(K_{\mathrm{d}}<1 \mu \mathrm{M}\right)$, the $K_{\mathrm{d}}$ value calculated from the data is viewed as an estimate only. The 4-HBA-CoA titration curves measured for the G114A and W89Y mutants were carried out to only partial saturation of the enzyme owing to the weak binding of the ligand. From these curves we estimate a half-saturation point somewhere between 50 and $100 \mu \mathrm{M} 4-\mathrm{HBA}-\mathrm{CoA}$.

The difference spectrum measured for the 4-MeBA-CoA complex of wild-type dehalogenase shows a single absorption peak centered at $302 \mathrm{~nm}$. This peak is clearly present in the spectra measured for the 4-MeBA-CoA-dehalogenase complexes formed with the D145A, F64L, F82L, H90Q, H81Q, and W137F mutants (Figure 8). The inability of the 

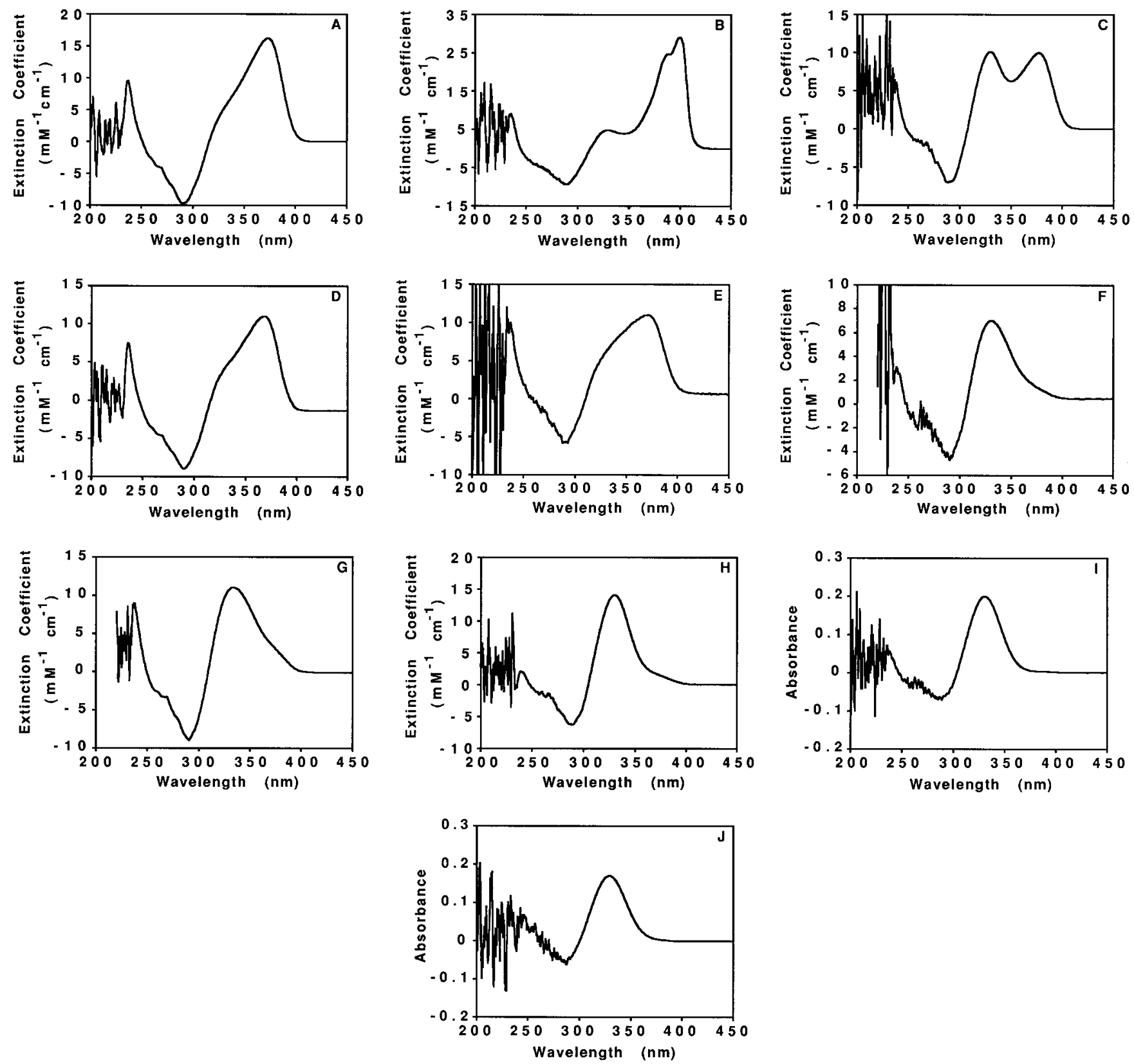

FIGURE 7: UV-Visible difference spectrum of the 4-HBA-CoA complex with (A) wild-type 4-CBA-CoA dehalogenase or the 4-CBA-CoA dehalogenase mutants (B) D145A, (C) W137F, (D) F64L, (E) F82L, (F) H81Q, (G) H90Q, (H) W89F, (I) W89Y, and (J) G114A. The spectrum measured for $0.5 \mathrm{~mL}$ of $200 \mu \mathrm{M}$ 4-HBA-CoA in $50 \mathrm{mM} \mathrm{K}{ }^{+}$-HEPES (pH 7.5) (compartment 1 ) and $0.5 \mathrm{~mL}$ of $50 \mu \mathrm{M}$ wild-type or mutant 4-CBA-CoA dehalogenase in $50 \mathrm{mM} \mathrm{K}^{+}$-HEPES (pH 7.5) (compartment 2) contained in a 1-mL quartz tandem cell was subtracted from the spectrum measured after the two compartments were mixed.

D145A dehalogenase mutant to initiate dehalogenation of 4-CBA-CoA provided us with the opportunity to measure the difference spectrum of the 4-CBA-CoA-D145A dehalogenase complex. As expected, this spectrum, shown in Figure 8I, is quite similar in appearance to that measured with the substrate analog, 4-MeBA-CoA.

Because of the weak binding affinity between the 4-MeBACoA ligand and the W89F dehalogenase mutant $\left(K_{\mathrm{i}}=35\right.$ $\mu \mathrm{M})$, the difference spectrum was measured with double the amount of enzyme $(50 \mu \mathrm{M})$. The 302-nm absorption peak is clearly present but considerably reduced in size (Figure $8 \mathrm{H})$. In contrast, no significant $302-\mathrm{nm}$ peak is found in the difference spectra measured for the 4-MeBA-CoA solutions of the G114A and W89Y dehalogenase mutants. Judging from the elevated $K_{\mathrm{m}}$ value $(100 \mu \mathrm{M}$, Table 1$)$ observed for the G114A mutant and the failure of $100 \mu \mathrm{M}$
4-HBA-CoA to saturate the W89Y mutant, we suspect that in both instances the concentration of enzyme-4-MeBACoA complex formed was quite low. Thus, inhibited 4-MeBA-CoA binding in these two mutants precludes evaluation of their ability to induce a spectral shift in the bound 4-MeBA-CoA.

The spectral titrations described above for the 4-HBA$\mathrm{CoA}$ ligand were also carried out with the 4-MeBA-CoA ligand. The dissociation constants determined from the titration data are reported in Table 1. (The binding of 4-MeBA-CoA to the G114A and W89Y mutants was too weak to measure by this method.)

Stopped-Flow Kinetic Analysis of the UV-Visible Spectral Properties of the 4-HBA-CoA Complexes Formed with WildType and W137F Mutant 4-CBA-CoA Dehalogenases. The $\mathrm{UV}$-visible absorption difference spectra of the 4-HBA-CoA 

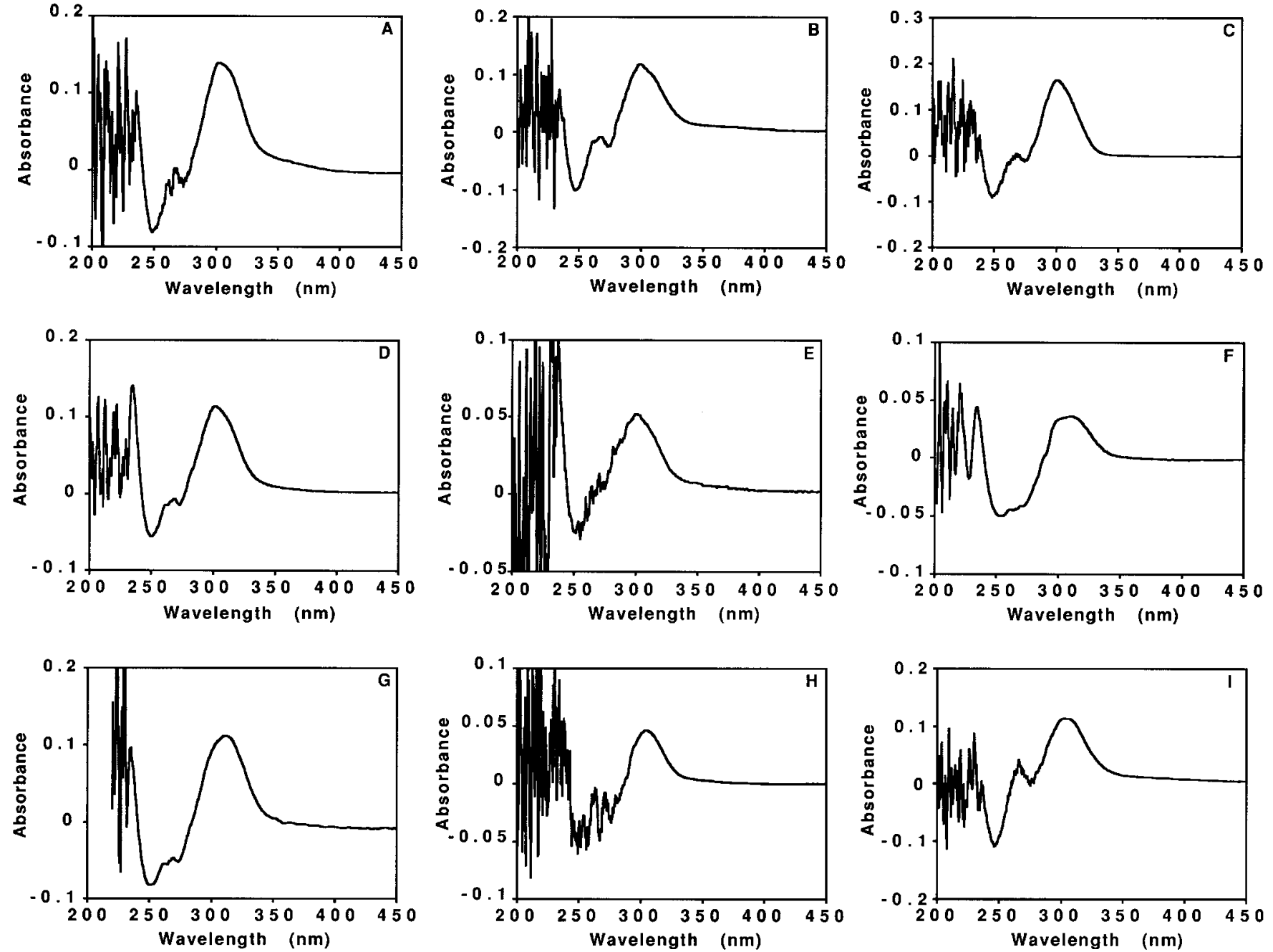

FIGURE 8: UV-Visible difference spectrum of the 4-MeBA-CoA complex with (A) wild-type 4-CBA-CoA dehalogenase or the 4-CBACoA dehalogenase mutants (B) D145A, (C) W137F, (D) F64L, (E) F82L, (F) H81Q, (G) H90Q, and (H) W89F. The spectrum measured for $0.5 \mathrm{~mL}$ of $200 \mu \mathrm{M}$ 4-MeBA-CoA in $50 \mathrm{mM} \mathrm{K}{ }^{+}$-HEPES (pH 7.5) (compartment 1) and $0.5 \mathrm{~mL}$ of $50 \mu \mathrm{M}$ wild-type or mutant 4-CBACoA dehalogenase (except W89F, where $100 \mu \mathrm{M}$ was used) in $50 \mathrm{mM} \mathrm{K}{ }^{+}$-HEPES (pH 7.5) (compartment 2) contained in a 1-mL quartz tandem cell was subtracted from the spectrum measured after the two compartments were mixed. (I) UV-Visible difference spectrum of the 4-CBA-CoA complex with D145A 4-CBA-CoA dehalogenase, measured under the same conditions described above with the exception that 4-CBA-CoA was substituted for 4-MeBA-CoA.

complexes of wild-type and mutant enzymes show a more or less pronounced absorption peak at 373 and/or at $330 \mathrm{~nm}$ (Figure 7). The complex formed with the D145A dehalogenase mutant shows these peaks plus a predominant peak at $400 \mathrm{~nm}$ (Figure 7B). The first indication that these peaks derive from distinct forms of the 4-HBA-CoA-dehalogenase complex arose from the odd behavior of the 4-HBA-CoA$\mathrm{W} 137 \mathrm{~F}$ dehalogenase complex. The difference spectrum of this complex, measured directly after the contents of the tandem cell were mixed, revealed a $373-\mathrm{nm}$ peak that was larger than the 330-nm peak, whereas, the spectrum measured minutes later showed the 330- and 373-nm peaks to be of equal size (Figure 7C). The slow apparent conversion of the 373-nm absorbing species to the 330-nm absorbing species has not been observed with any of the other dehalogenase mutants nor with the wild-type enzyme.

Direct evidence for the formation of two distinct forms of the 4-HBA-CoA-dehalogenase complex was obtained from transient kinetic studies of the binding reaction of 4-HBA-CoA with wild-type and W137F dehalogenase. The rates of formation of the two forms of the complex were measured using a stopped-flow spectrophotometer to monitor the binding reaction at 330 and $373 \mathrm{~nm}$. For the W137F mutant, the kinetic traces reflect rapid formation of the 373$\mathrm{nm}$ absorbing complex $\left(k=240 \mathrm{~s}^{-1}\right)$ followed by comparatively slow conversion of it to the 330-nm absorbing complex $\left(k=18 \mathrm{~s}^{-1}\right.$ ) (Figure 9A). The binding curves of the wildtype dehalogenase, on the other hand, show equally rapid ( $k$ $=260 \mathrm{~s}^{-1}$ ) formation of the two absorption complexes (Figure 9B). Further information regarding the two forms of the enzyme-4-HBA-CoA complex was obtained by carrying out the ${ }^{13} \mathrm{C}$ NMR studies described below.

${ }^{13} \mathrm{C}$ NMR Spectra of [thioester- $\left.{ }^{13} \mathrm{C}=\mathrm{O}\right]-4-\mathrm{HBA}-\mathrm{CoA}$ Bound to the Active Sites of Wild-Type and Mutant 4-CBA-CoA Dehalogenases. The ${ }^{13} \mathrm{C} \mathrm{NMR}$ spectra of the [thioester$\left.{ }^{13} \mathrm{C}=\mathrm{O}\right]-4-\mathrm{HBA}-\mathrm{CoA}$ complexes of wild-type and mutant dehalogenases (W137F, H90Q, H81Q, and D145A) are presented in Figure 10. In a previous study, we had reported that the ${ }^{13} \mathrm{C}=\mathrm{O}$ signal from the solvated ligand resonates at 193.2 ppm (Taylor et al., 1995) whereas the ${ }^{13} \mathrm{C}=\mathrm{O}$ signal from the wild-type dehalogenase $-\left[\right.$ thioester $\left.-{ }^{13} \mathrm{C}=\mathrm{O}\right]-4-\mathrm{HBA}$ CoA complex resonates at 196.0 ppm. As is shown in Figure $10 \mathrm{E},{ }^{3}$ the W137F dehalogenase $-\left[\right.$ thioester- $\left.{ }^{13} \mathrm{C}=\mathrm{O}\right]-4-\mathrm{HBA}-$ CoA complex displays two resonances, one centered at 198.4 ppm and the other at $194.6 \mathrm{ppm}$. As with the wild-type dehalogenase (Figure 10B), the [thioester- $\left.{ }^{13} \mathrm{C}=\mathrm{O}\right]-4-\mathrm{HBA}-$ 

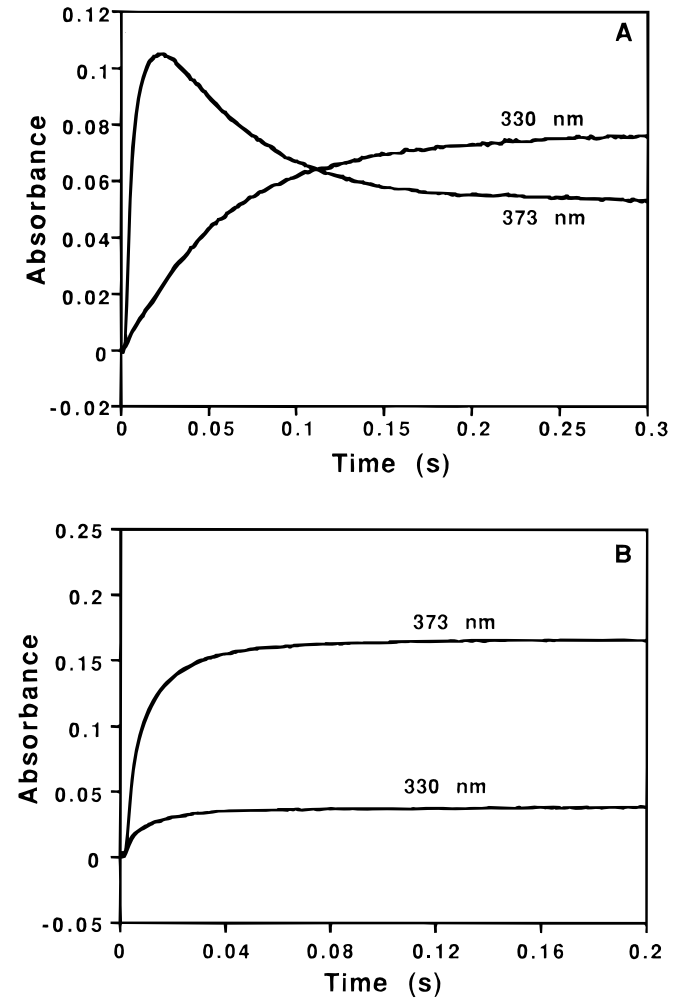

FIGURE 9: Progress curves of the binding reaction of $24 \mu \mathrm{M}$ 4-HBA-CoA with $24 \mu \mathrm{M}$ W137F 4-CBA-CoA dehalogenase (A) or wild-type 4-CBA-CoA dehalogenase (B) in $50 \mathrm{mM} \mathrm{K}^{+}$-HEPES $\left(\mathrm{pH} 7.5,25^{\circ} \mathrm{C}\right)$. The change in solution absorbance at 373 and $330 \mathrm{~nm}$ is plotted as a function of time after reactant mixing in a stopped-flow instrument.

CoA complex formed with the other mutant enzymes (H81Q, H90Q, and D145A; Figure 10C,D,F) showed a single ${ }^{13} \mathrm{C}=\mathrm{O}$ resonance; however, it was shifted from that deriving from the ligand bound to the wild-type enzyme.

Examination of the ${ }^{13} \mathrm{C}$ NMR spectra of H90Q, H81Q, and $\mathrm{D} 145 \mathrm{~A}$ dehalogenase complexes of $\left[\right.$ thioester $\left.{ }^{13} \mathrm{C}=\mathrm{O}\right]$ 4-HBA-CoA shown in Figure 10 allows a correlation to be drawn between the benzoyl $\lambda_{\max }$ and the ${ }^{13} \mathrm{C}=\mathrm{O}$ chemical shift; namely, that the longer wavelength absorption correlates with the smaller chemical shift. For instance, the UVvisible difference spectra of the H81Q and H90Q dehalogenase complexes (Figure 7F,G) contain the 330-nm absorption peak but not the 373-nm peak. Both mutant complexes give rise to ${ }^{13} \mathrm{C}=\mathrm{O}$ NMR signals at $199.0 \mathrm{ppm}$ which match closely with the downfield signal of the W137F dehalogenase $-\left[\right.$ thioester $\left.-{ }^{13} \mathrm{C}=\mathrm{O}\right]-4-\mathrm{HBA}-\mathrm{CoA}$ complex at $198.4 \mathrm{ppm}$ (Figure 10E). The 194.6-ppm signal of the W137F dehalogenase $-\left[\right.$ thioester $\left.{ }^{13} \mathrm{C}=\mathrm{O}\right]-4-\mathrm{HBA}-\mathrm{CoA}$ complex must then correspond to the 373-nm absorption band. Indeed, the chemical shift of the ${ }^{13} \mathrm{C}=\mathrm{O}$ of the D145A dehalogenase $-\left[\right.$ thioester $\left.-{ }^{13} \mathrm{C}=\mathrm{O}\right]-4-\mathrm{HBA}-\mathrm{CoA}$ complex is $186.5 \mathrm{ppm}$, an average of the signals arising from the three different states represented by the 330-, 373-, and 400-nm absorptions (Figure 7B) (and heavily weighted by the latter).

\footnotetext{
${ }^{3}$ We were unable to measure the chemical shift of the ${ }^{13} \mathrm{C}=\mathrm{O}$ signal from $\left[\right.$ thioester $\left.-{ }^{13} \mathrm{C}=\mathrm{O}\right] 4-\mathrm{HBA}-\mathrm{CoA}$ bound to the W89F dehalogenase mutant. The purified protein contained a trace of thioesterase activity that we could not remove, and within the time frame that it took to accumulate the spectrum, the ligand had been hydrolyzed.
}

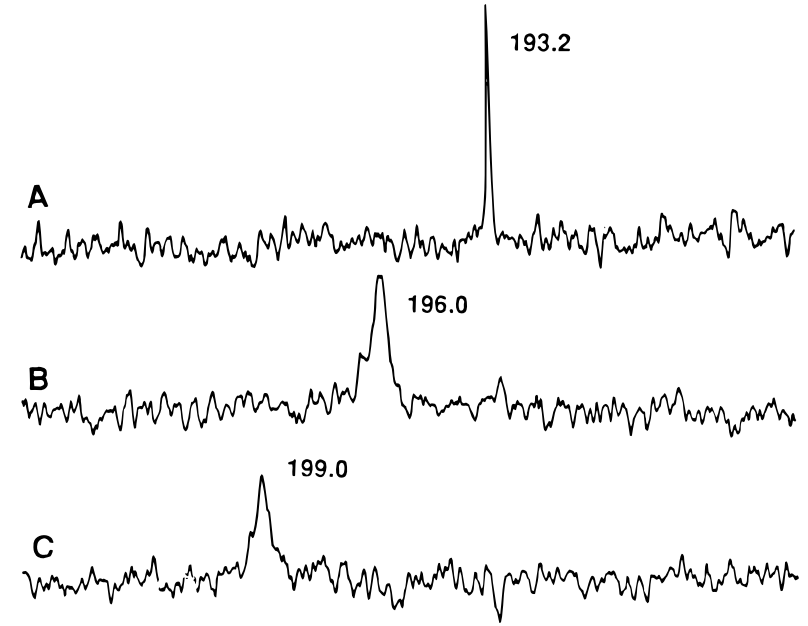

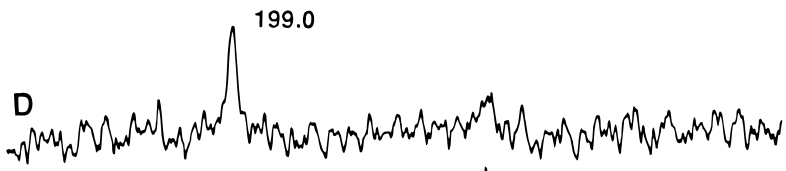

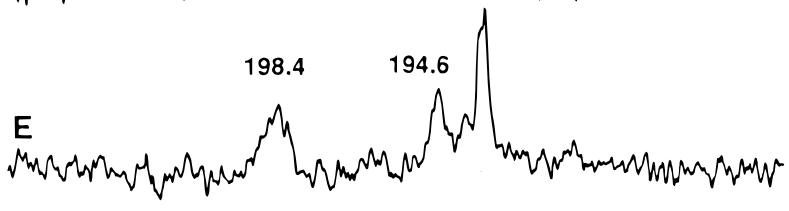
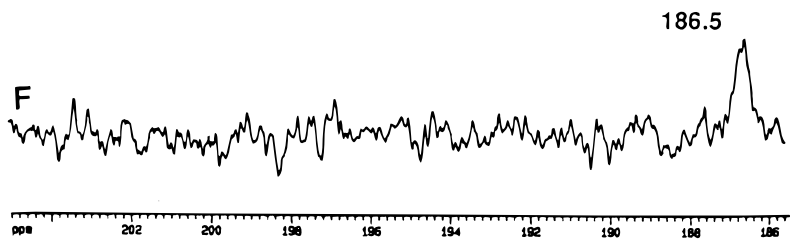

FIGURE 10: ${ }^{13} \mathrm{C}$ NMR (125.77-MHz) spectrum of $1.0 \mathrm{mM}$ [thioester- $\left.{ }^{13} \mathrm{C}=\mathrm{O}\right]-4-\mathrm{HBA}-\mathrm{CoA}$ in $5 \mathrm{mM} \mathrm{K}{ }^{+}$-HEPES/0.5 mM DTT buffer ( $\mathrm{pH}$ 7.5) without 4-CBA-CoA dehalogenase (A) and with $1.5 \mathrm{mM}$ (B) wild-type, (C) H81Q, (D) H90Q, (E) W137F, and (F) D145A 4-CBA-CoA dehalogenase.

\section{DISCUSSION}

The benzoyl ring of solvated 4-MeBA-CoA gives rise to two overlapping absorption peaks at 257 and $274 \mathrm{~nm}$ which undergo a substantial red shift $\left(\lambda_{\max }=302 \mathrm{~nm}\right)$ when the ligand binds to the active site of 4-CBA-CoA dehalogenase (Figure 2B). The benzoyl ring of 4-HBA-CoA, on the other hand, gives rise to a major absorption band centered at 290 $\mathrm{nm}$, which, upon ligand binding to the enzyme active site, is shifted to 330 or $373 \mathrm{~nm}$ (Figure 2A). Model studies, in which the absorption properties of 4-methylbenzoyl- and 4-hydroxybenzoyl thioesters in organic solvents were measured, have ruled out simple desolvation as an explanation for the red shifts observed for the enzyme-bound species (Taylor et al., 1996). As a working model for catalysis, we had attributed these shifts to active-site-induced polarization of the benzoyl ring $\pi$-electron density (Taylor et al., 1995). In this study, we have focused on identifying the active-site residues responsible for the proposed ring polarization.

Replacement of the two active-site Trp residues (W137F and $\mathrm{W} 89 \mathrm{~F}$ ) and two Phe residues (F64L and F82L) that form the hydrophobic binding pocket of the benzoyl ring (Figure 1B) with other hydrophobic residues had a small to moderate inhibitory effect on ligand binding and catalysis (Table 1) and had little to no effect on the induction of the red shift in 4-MeBA-CoA (Figure 8). Furthermore, the W137F, F64L, and F82L dehalogenase-4-HBA-CoA complexes gave rise 
to difference spectra which closely resembled that measured with the wild-type enzyme (Figure 7). The difference spectrum of the W89F dehalogenase-4-HBA-CoA complex showed (as did the spectra measured for the complexes formed with H90Q and H81Q) a 330-nm absorption band but not the 373-nm band. At present, the significance of this observation is unclear as we know little of the electronic/ structural differences that distinguish the 330- and 373-nm absorbing forms of the enzyme-4-HBA-CoA complexes. ${ }^{4}$ The slow interconversion that takes place between the two forms of the W137F dehalogenase-4-HBA-CoA complex (Figure 9) allowed us to measure the ${ }^{13} \mathrm{C}$ NMR chemical shift of the benzoyl $\mathrm{C}=\mathrm{O}$ signal derived from each (Figure 10). While the signal from the 373-nm absorbing species appears roughly $1 \mathrm{ppm}$ downfield from that of the solvated ligand, the signal from the 330-nm absorbing species is shifted 5 ppm downfield. We note that the extent to which the benzoyl $\mathrm{C}=\mathrm{O}$ carbon nucleus experiences deshielding within the active-site environment does not correlate with that of the induced ring polarization (as measured by the magnitude of the induced red shift: 31 vs $88 \mathrm{~nm}$ ). A meaningful explanation of these effects cannot be offered at this time. We are, however, hopeful that the results from ongoing X-ray crystallographic and Raman studies of the mutant enzyme-4-HBA-CoA complexes may ultimately provide substantial insight into this problem. Overall, the F64L, F82L, W89F, and W137F mutants retain substantial catalytic activity and the ability to induce the diagnostic red shift in the absorption band from the bound benzoyl ligand. The W89Y mutant, on the other hand, is inhibited in catalysis and ligand binding, suggesting that hydrophobicity more than packing may be critical for the benzoyl ring binding/ activation.

The mutations made at the catalytic Asp and His residues (D145A and H90Q) predictably inhibited catalysis but did not significantly reduce ligand binding or interfere with the induction of the red shift in bound 4-MeBA-CoA. On the other hand, we did note the appearance of a third absorption band at $400 \mathrm{~nm}$ in the UV-visible difference spectrum of the D145A dehalogenase-4-HBA-CoA complex and the absence of the 373-nm absorption band from that of the H90Q dehalogenase-4-HBA-CoA complex. Nevertheless, it is not unreasonable to conclude, independent of the observed effects on the multiplicity of 4-HBA-CoA absorption bands, that neither the D145 nor the H90 residue is required for the active-site-induced red shift in ligand benzoyl ring absorption.

By the process of elimination we are left with the two $\mathrm{H}$-bonds formed between the benzoyl ring $\mathrm{C}=\mathrm{O}$ and the backbone amide $\mathrm{NH}$ of residues G114 and Phe64 (implicated by the X-ray crystal structure of the wild-type dehalogenase4-HBA-CoA complex; Benning et al., 1996) to account for the ring polarization. As illustrated in Figure 11, Phe64 is located within a loop that makes a close approach to the benzoyl $\mathrm{C}=\mathrm{O}$ but is otherwise not an integral part of the

\footnotetext{
${ }^{4}$ Two possible scenarios that we have considered are (1) that the relative orientation of the hydroxybenzoyl ring and the helix dipole are different in the two forms and (2) that $\pi-\pi$ or $\pi-\sigma$ interactions between the hydroxybenzoyl ring and the aromatic residues which make up the benzoyl ring binding pocket may occur in one form more so than in the other [for descriptions and specific examples of $\pi-\pi$ and $\pi-\sigma$ interactions in aromatic systems, see Hunter and Sanders (1990) Ishida et al. (1993), and Nagata et al. (1995)].
}

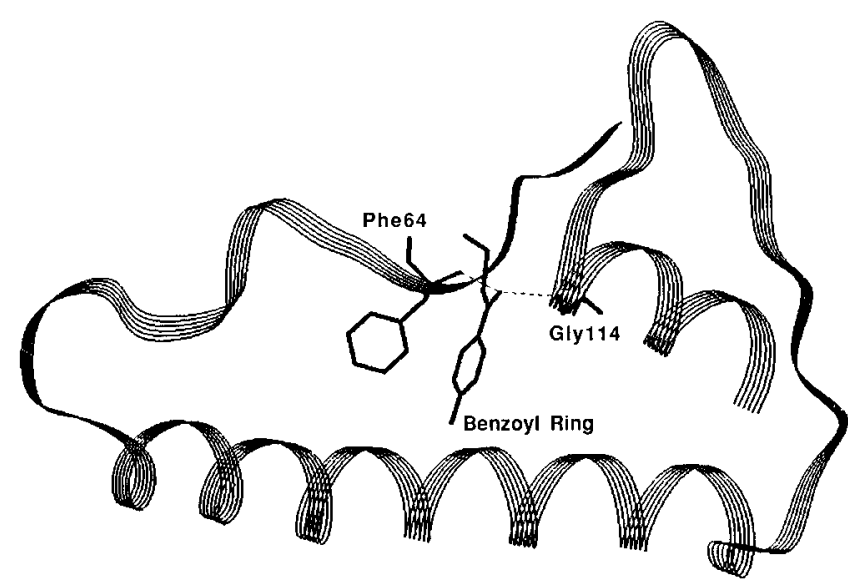

FIGURE 11: Illustration, derived from the crystal structure of the wild-type 4-CBA-dehalogenase-4-HBA-CoA complex determined at $1.8 \mathrm{~A}$ (Benning et al., 1996), showing the arrangement of the Phe64 loop, G114, and the 114-121 $\alpha$-helix relative to the ligand benzoyl ring.

catalytic machinery. Gly114 is the N-terminal residue of $\alpha$-helix 114-121 whose positive pole is directed at the benzoyl $\mathrm{C}=\mathrm{O}$. The two amide backbone $\mathrm{H}$-bonds plus a possible contribution from the helix dipole constitutes a sizable electron-withdrawing force (Hol, 1985; Aqvist et al., 1991; Baker \& Hubbard, 1984; Sali et al., 1988; Nicholson et al., 1991; Doran et al., 1996; Doran \& Carey, 1996). The significance of these interactions in dehalogenase catalysis is underscored by the conservation of the Phe64 loop and Gly114 $\alpha$-helix among the three known dehalogenase sequences (Lai, 1996) and the sequences of the enzymes of the enoyl-CoA family (Babbitt et al., 1992; DunawayMariano \& Babbitt, 1994; Muller-Newen et al., 1995). This family includes 2-enoyl-CoA hydratase, $\Delta^{3}$-cis, $\Delta^{2}$-transenoyl-CoA isomerase, carnitine racemase, naphthoate synthase, 4-CBA-CoA dehalogenase, and several other proteins whose (catalytic) functions have not yet been identified. Common to this group of catalyzed reactions is the apparent formation of an enolate thioester intermediate and/or transition state. We presume that the placement of the $\alpha$-helix and the two backbone amide hydrogens is conserved among this group of enzymes to stabilize the enolate transition state/ intermediate through favorable charge-dipole interaction with the thioester $\mathrm{C}=\mathrm{O}$.

Experimental verification of the individual contributions made by the backbone amide $\mathrm{NH}$ hydrogen bonds donated by Phe64 and Gly114 and the dipole interaction with $\alpha$-helix $114-121$ is, as we have discovered in the present study, difficult to obtain. Replacement of the strictly conserved Phe64 residue with Leu had a minimal effect on the ligand spectral perturbations. Moreover, the small to moderate kinetic/binding effects that were observed can be attributed to the alteration of packing within the hydrophobic benzoyl binding site expected to result from the substitution of the Phe aromatic side chain with the Leu side chain. The positioning of the Phe64 within the loop (shown in Figure 11) apparently permits substitution of the Leu without significant alteration of the backbone conformation (i.e., leading to disruption of $\mathrm{H}$-bonding).

Gly114 is the central residue of a 3-Gly tight turn out of the 114-121 $\alpha$-helix (Figure 6). Gly115 is strictly conserved among the sequences of the enoly-CoA enzyme family, yet Gly114 and Gly113 are not (Ala substitutions exist). 
Nevertheless, the conservative Ala for Gly substitution made at position 114 had a very disruptive effect on catalysis. However, since ligand binding is also inhibited in the G114A mutant, quantitative assessment of ring polarization by spectral methods is precluded. The challenge of designing structure-function studies which will allow us to dissect the contributions made by the H-bonds from G114 and Phe64 to the benzoyl $\mathrm{C}=\mathrm{O}$, and by the electrostatic interaction provided by the $\alpha$-helix dipole, to the polarization of the benzoyl ring remains for future studies.

\section{REFERENCES}

Adriaens, P., Kohler, H. P. E., Kohler, S. D., \& Focht, D. D. (1989) Appl. Environ. Microbiol. 55, 887.

Anderson, K. S., Sikorski, J. A., \& Johnson, K. A. (1988) Biochemistry 27, 1604.

Aqvist, J., Luecke, H., Quiocho, F. A., \& Warshel, A. (1991) Proc. Natl. Acad. Sci. U.S.A. 88, 2026.

Babbitt, P. C., Kenyon, G. L., Martin, B. M., Charesr, H., Sylvestre, M., Scholten, J. D., Chang, K.-H., Liang, P. H., \& DunawayMariano, D. (1992) Biochemistry 31, 5594.

Baker, E. N., \& Hubbard, R. E. (1984) Prog. Biophys. Mol. Biol. 44, 97.

Benning, M., Taylor, K. L., Liu, R. Q., Yang, G., Xiang, H., Wesenberg, G., Dunaway-Mariano, D., \& Holden, H. M. (1996) Biochemistry 35, 8103.

Bradford, M. (1976) Anal. Biochem. 72, 248.

Chang, K.-H., Liang, P.-H., Beck, W., Scholten, J. D., \& DunawayMariano, D. (1992) Biochemistry 31, 5605.

Cleland, W. W. (1979) Methods Enzymol. 63, 84.

Copley, S. D., \& Crooks, G. P. (1992) Appl. Environ. Microbiol. $58,1385$.

Doran, J. D., \& Carey, P. R. (1996) Biochemistry 35, 12495.

Doran, J. D., Tonge, P. J., Mort, J. S., \& Carey, P. R. (1996) Biochemistry 35, 12487.
Dunaway-Mariano, D., \& Babbitt, P. C. (1994) Biodegradation 5, 259.

Groenewegen, P. E. J., van den Tweel, W. J. J., \& de Bont, J. A. M. (1992) Appl. Microbiol. Biotechnol. 36, 541.

Hol, W. G. J. (1985) Prog. Biophys. Mol. Biol. 45, 149.

Ishida, T., Nagata, H., In, Y., Doi, M., Inove, M., Extine, M. W., \& Wakahara, A. (1993) Chem Pharm. Bull 41(3) 433-438.

Jaffe, E., \& Markham, G. D. (1987) Biochemistry 26, 4258.

Lai, S. Y. (1996) Ph.D. Thesis, University of Maryland.

Liang, P.-H., Yang, G., \& Dunaway-Mariano, D. (1993) Biochemistry 32, 12245.

Liu, R.-Q., Liang, P.-H., Scholten, J., \& Dunaway-Mariano, D. (1995) J. Am. Chem. Soc. 117, 5003.

Merkel, S. M., Eberhard, A. E., Gibson, J., \& Harwood, C. S. (1989) J. Bacteriol. 171, 1.

Mieyal, J. J., Webster, L. T., \& Siddigui, U. A. (1974) J. Biol. Chem. 249, 2633.

Muller-Newen, G., Janssen, V., \& Stoffel, W. (1995) Eur. J. Biochem. 228, 68.

Nagata, H., In, Y., Doi, M., \& Ishida, T. (1995) Acta Crystallogr. B51, 1051.

Nicholson, H., Anderson, D. E., Dao-pin, S., \& Matthews, B. W. (1991) Biochemistry 30, 9816.

Sali, D., Bycroft, M., \& Fersht, A. R. (1988) Nature 335, 740.

Scholten, J. D., Chang, K.-H., Babbitt, P. C., Charest, H., Sylvestre, M., \& Dunaway-Mariano, D. (1991) Science 253, 182.

Taylor, K. L. (1996) Ph.D. Thesis, University of Maryland.

Taylor, K. L., Liu, R.-Q., Liang, P.-H., Price, J., Dunaway-Mariano, D., Tonge, P. J., Clarkson, J., \& Carey, P. R. (1995) Biochemistry 34, 13881.

Yang, G., Liang, P.-H., \& Dunaway-Mariano, D. (1994) Biochemistry 33, 8527.

Yang, G., Liu, R.-Q., Taylor, K. L., Xiang, H., Price, J., \& Dunaway-Mariano, D. (1996) Biochemistry 35, 10879.

BI962765I 